\title{
Development and Sizing of the JWST Integrated Science Instrument Module (ISIM) Metering Structure
}

\author{
Cengiz O. Kunt ${ }^{\mathrm{a} *}$, John Johnston ${ }^{\mathrm{b}}$, Andrew Bartoszyk ${ }^{\mathrm{a}}$, Steve Hendricks ${ }^{\mathrm{a}}$ \\ ${ }^{a}$ Swales Aerospace, 5050 Powder Mill Rd, Beltsville, MD 20705; \\ bASA Goddard Space Flight Center, Code 542, Greenbelt, Maryland 20771
}

\begin{abstract}
The JWST Integrated Science Instrument Module (ISIM) includes a large metering structure (approx. $2 \mathrm{~m} \mathrm{x}$ $2 \mathrm{~m} \times 1.5 \mathrm{~m}$ ) that houses the science instruments and guider. Stringent dimensional stability and repeatability requirements combined with mass limitations led to the selection of a composite bonded frame design comprised of biased laminate tubes. Even with the superb material specific stiffness, achieving the required frequency for the given mass allocations in conjunction with severe spatial limitations imposed by the instrument complement has proven challenging. In response to the challenge, the ISIM structure team considered literally over 100 primary structure topology and kinematic mount configurations, and settled on a concept comprised of over $70 \mathrm{~m}$ of tubes, over 50 bonded joint assemblies, and a "split bi-pod" kinematic mount configuration. In this paper, we review the evolution of the ISIM primary structure topology and kinematic mount configuration to the current baseline concept.
\end{abstract}

Keywords: ISIM, JWST, Metering Structure, Launch, Cryogenic, Distortion, Finite Element Analysis.

\section{INTRODUCTION}

The James Webb Space Telescope (JWST) is an infrared optimized space observatory that will study the origin and evolution of galaxies, stars and planetary systems following its planned launch in 2013 (Reference 1). The JWST observatory, Figure 1, consists of an optical telescope element (OTE), an integrated science instrument module (ISIM), and a space vehicle that includes a spacecraft bus and a deployable sunshield. The ISIM, Figure 2/Reference 2, consists of structure and thermal subsystems, a Near Infrared Camera (NIRCam), a Near Infrared Spectrograph (NIRSpec), a Mid-Infrared Instrument (MIRI), and a Fine Guidance Sensor (FGS). The focus of this paper is the ISIM structure subsystem that consists of a metering structure that supports the science instruments and kinematic mounts that attach the ISIM to the OTE. The ISIM structure successfully completed a preliminary design review in January 2005 and is currently in the detailed design phase of its development. This paper discusses ISIM structure requirements and challenges, the evolution of the design, structural modeling approaches, and baseline performance predictions.

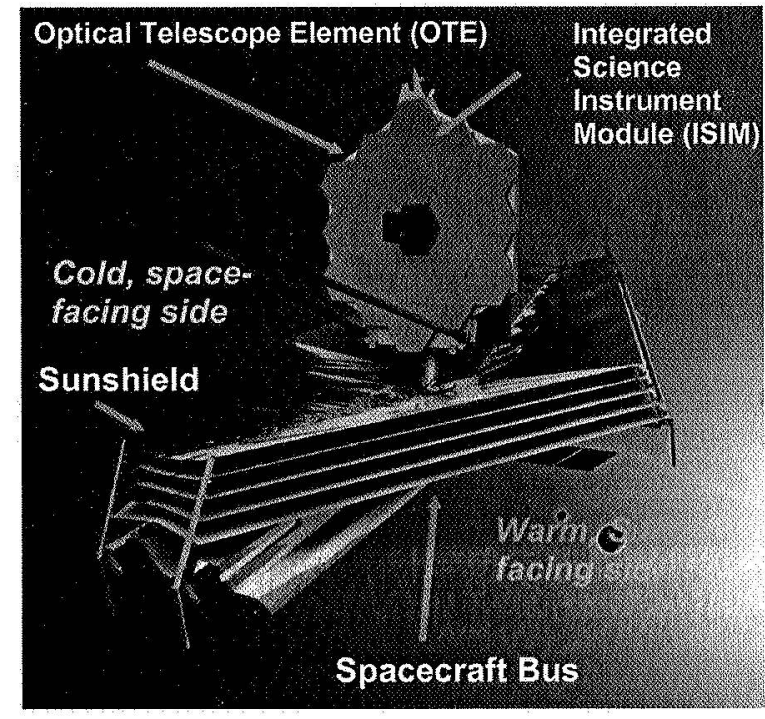

Figure 1: James Webb Space Telescope (JWST)

•ckunt@swales.com; phone: 1302 902-4214; fax 1302 902-4112; swales.com 


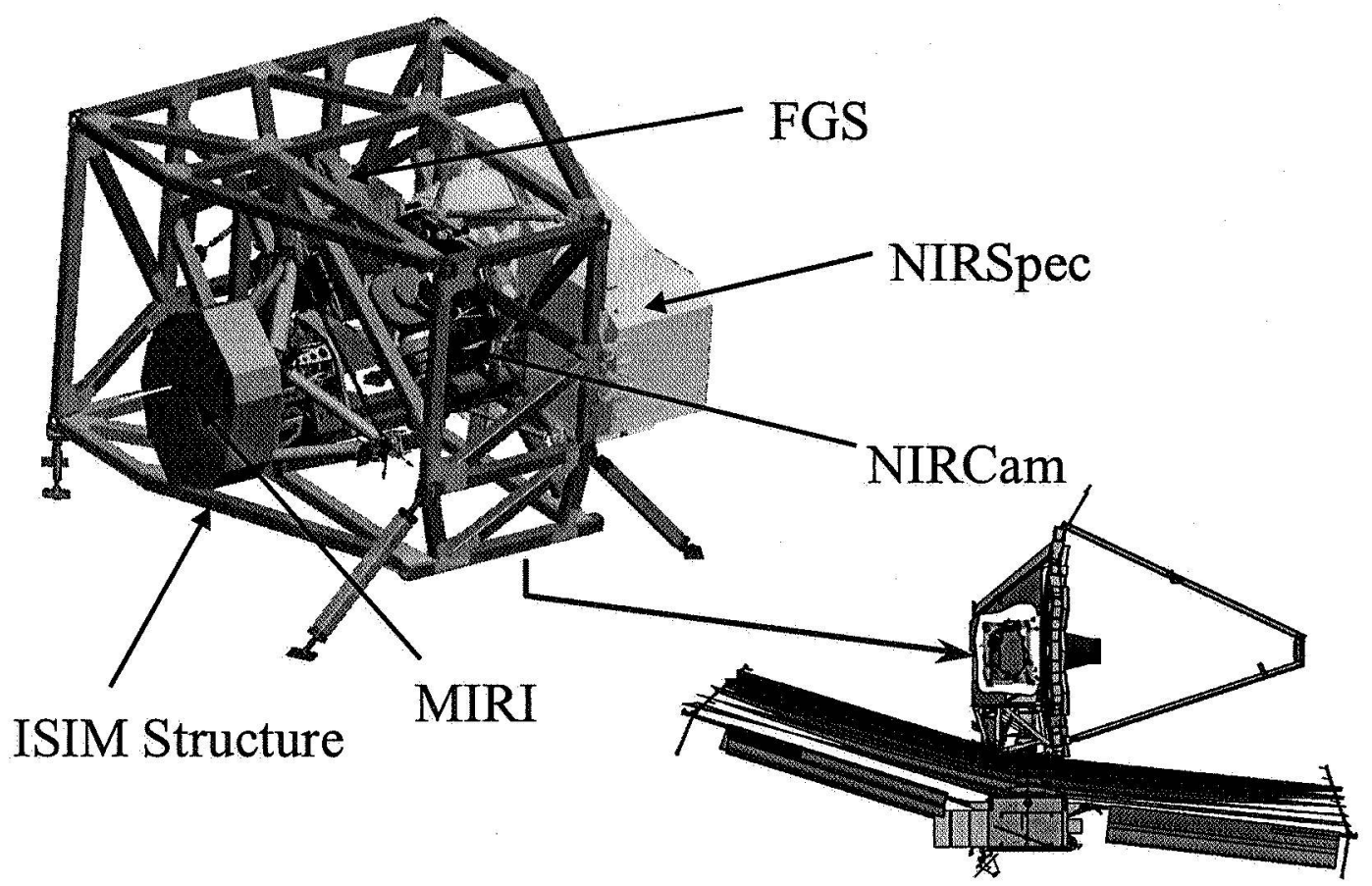

Figure 2: Integrated Science Instrument Model (ISIM)

\section{ISIM STRUCTURE REQUIREMENTS AND CHALLENGES}

The design of the ISIM structure must accommodate interfaces to the science instruments and OTE while meeting a number of critical requirements, including: mass, minimum frequency, structural integrity, and distortion performance. The combination of stiffness and distortion requirements with mass limitations led to the selection of a bonded composite frame construction for the ISIM structure. A summary of key requirements that have driven the design are as follows. The total design-to mass allocation for the ISIM is $1140 \mathrm{~kg}$ with a sub-allocation to the ISIM structure subsystem of $300 \mathrm{~kg}$. The minimum natural frequency of the ISIM fixed at the OTE interface must be greater than $25 \mathrm{~Hz}$.

Structural integrity must be maintained under two challenging environments: launch and cooldown to cryogenic temperatures. Structural integrity of composite bonded joints under launch and thermal loads is a key challenge in the design of the ISIM structure. Reference 3 discusses this aspect of the ISIM structure in detail. Figure 3 lists launch limit loads used for sizing the primary structure. Instruments and ISIM interfaces to the instruments are sized under a set of higher design limit loads also listed in Figure 3 . The cryogenic temperatures that the structure must be designed to accommodate include a $22 \mathrm{~K}$ survival temperature, an operating temperature in the range of 32 to $37 \mathrm{~K}$, and shifts in the operational temperature of $0.25 \mathrm{~K}$. Design Factor of Safety (FS) of 1.5 is used for ultimate failure of composites, 1.4 for metals and 1.25 for yield.

The distortion performance of the structure is subject to stringent requirements in terms of ground to orbit alignment and operational stability due to shifts in the operating temperature resulting from observatory repointing. Distortion performance requirements are specified in terms of allowable motions at the science instrument interfaces. Ground-to-orbit distortions are limited to $6.0 \mathrm{E}-1 \mathrm{~mm}$ in displacement and 6 arcmin in rotation, while operational stability distortions are limited to $3.0 \mathrm{E}-4 \mathrm{~mm}$ in displacement and $6.0 \mathrm{E}-3$ arcmin in rotation. The following sections describe the evolution of the ISIM primary structure's design to the current baseline. 


\begin{tabular}{|c|c|c|c|}
\hline \multicolumn{3}{|c|}{$\begin{array}{c}\text { Primary Structure } \\
\text { Launch Limit Load Factors (g) }\end{array}$} & \multirow{6}{*}{$\begin{array}{l}\text { Instruments \& Interfaces } \\
\text { Launch Limit Load Factors } \\
\text { Based on an Enveloping Mass- } \\
\text { Acceleration Curve and weight } \\
\text { of instrument: } \\
\text { - MIRI: } \pm 13.5 \mathrm{~g} \text { one axis } \\
\quad \text { at a time, } \\
\text { - Other instruments: } \pm 12.0 \mathrm{~g} \\
\text { one axis at a time. }\end{array}$} \\
\hline Load Case & Thrust (V3) & Lateral $^{\mathrm{a}}$ & \\
\hline Max Comp. & -6.44 & 1.5 & \\
\hline Max Tension & +3.25 & 1.5 & \\
\hline Max Lateral & -3.65 & 3.0 & \\
\hline \multicolumn{3}{|c|}{ a - Lateral loads are swept in V1-V2 plane } & \\
\hline
\end{tabular}

Figure 3: ISIM Launch limit load factors for the primary structure and for the instruments and instrument interfaces. Coordinate axes (V1, V2, V3) are shown in Figure 4.

\section{PRIMARY STRUCTURE}

\subsection{Primary Structure Lay Out \& Load Paths}

A three-dimensional frame type construction is used for the ISIM primary structure as shown in the CAD view of Figure 4. Plate construction has been considered and abandoned in favor of the frame because preliminary trade studies demonstrated that frame is structurally more efficient, provides better access to the instruments and lends itself better to supporting a small number of discrete attachment points for the instruments.

The baseline structure configuration is close to being a three dimensional truss but deviates from it due to moment continuity at its joints and due to open bays needed for instrument integration, access, and stay-out zones. All primary load lines intersect at all structural joints. Open bays degrade stiffness and therefore are stiffened as much as possible through nearby frame and wing structures. Removable members are not used to stiffen the open bays in view of repeatability and distortion concerns. Trusses in different planes are staggered to simplify some joints.

\subsection{Primary Structure Members}

Primary structure tubular members are of square cross section with rounded corners. Flat-to-flat dimension is $75 \mathrm{~mm}$ and the wall thickness is $4.6 \mathrm{~mm}$ for all members. Tubes are made of a carbon fiber reinforced laminated composite material system. The primary reasons for this choice are CTE, stiffness, and weight. The material is a biased lay-up using two different unidirectional tapes; M55J/954-3 and T300/954-3, resulting in a high axial stiffness along the length of the tubes, which is important to meet the minimum natural frequency requirement. The material is also designed to result in a near zero CTE along the axis of the tubes for distortion and stability performance. Material is tailored to have a high stiffness per unit weight along the axis of the tubes to help meet the minimum fundamental frequency requirement while staying within the structure weight budget. With a total length of approximately $75 \mathrm{~m}$ and a weight of approximately $130 \mathrm{~kg}$, the primary tubular members consume about half of the structure weight budget.

\subsection{Kinematic Mounts}

ISIM is mounted on the telescope structure through Kinematic Mounts (KMs) in order to minimize transmission of thermally or mechanically induced distortions to and from ISIM. The KMs consist of two bipods and two monopods as indicated in Figure 4 and constrain the six primary rigid body motions of ISIM. KMs are flexural elements with neck-down areas designed to minimize the secondary shear and moment stiffnesses resulting in a close-to-ideal kinematic constraint system. Driving requirements for the 
KMs are launch strength, high primary stiffness, and "low" reactions under cool-down to operating temperature.

\subsection{Primary Structure Joints}

Structural joints between the composite material members are critical elements of the primary structure. These are typically the areas of the primary structure with the highest stresses under launch and cool-down environments and their design and analysis targets an optimal balance between strength and weight. Putting fastener holes through the composite parts and using bolts and pins to directly fasten to composite parts is avoided due to the low bearing strength and through-the-thickness compressive strength of composites. Instead, adhesive bonding is used and all bolts and pins are kept in the metallic parts. It was determined by analysis that all the metallic parts that are bonded to the composite tubes need to be INVAR since its CTE approximately matches those of the composite tubes and enables the extreme temperature drop that the structure needs to undergo with no or minimal structural degradation at these joints. Structural adhesive EA-9309 is selected for use at all the bonded joints. Even though it is not as strong as EA-9394, another common adhesive, it is deemed superior to it in this application based on its higher elongation capability and lower stiffness, which helps with thermal survivability.

\subsubsection{Plug and Saddle Joints}

Use of metallic joints results in stronger and stiffer joint, however added weight needs to be watched closely. ISIM primary structure uses metallic joints only where they are absolutely necessary for structural integrity. Metallic joints are of plug and saddle type as illustrated in the close-up views of Figures 4(a) and (b). Plugs joints are used to structurally connect three or more tubes that lie in different planes and intersect at the same load center. Some of the plug joints also provide flanges for mechanical fastening of the kinematic mounts using tension bolts and shear pins. Tubes are bonded over the prongs of a plug joint. Saddles are bonded over the tubes and provide mounting points for ISIM instruments.

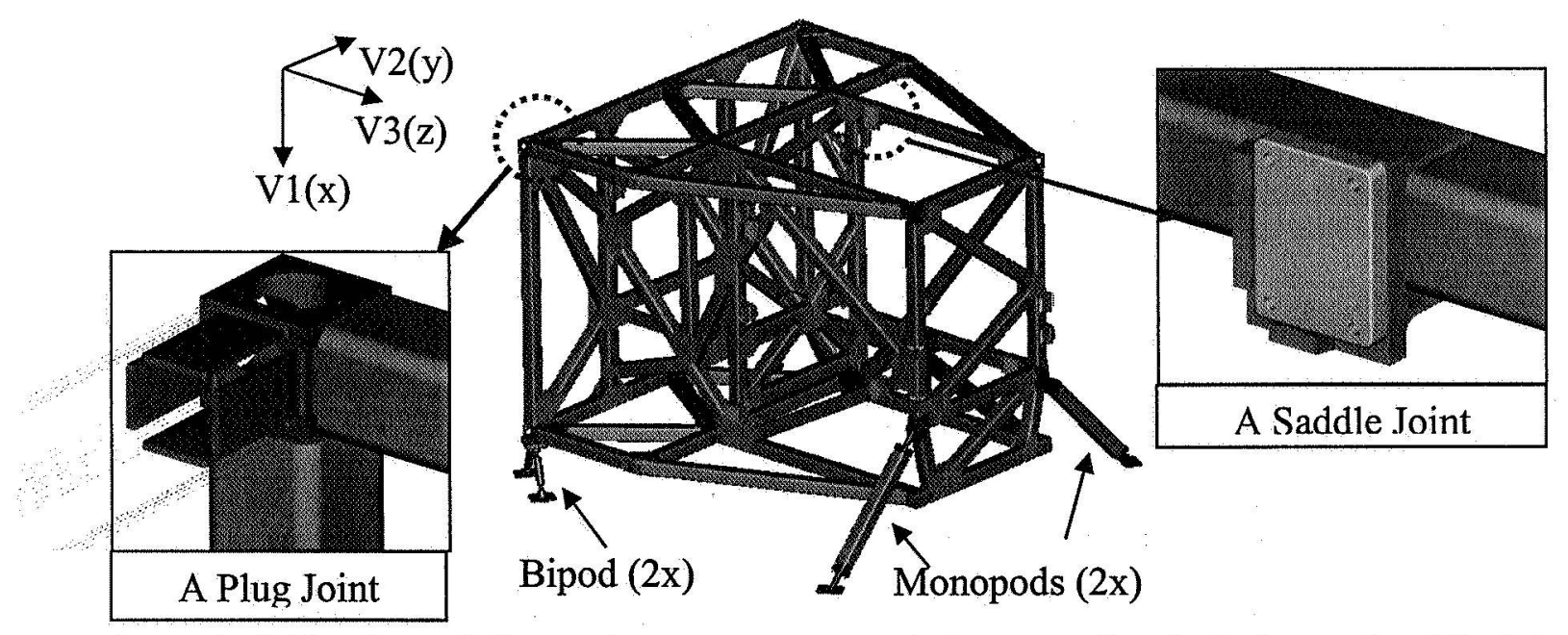

Figure 4: CAD view of ISIM primary structure and close-up of typical plug and saddle joints.

\subsubsection{Gusset \& Shear Clip Joints}

Most of the joints of the ISIM structure use gussets and shear clips bonded to tubes as seen in Figure 4. Gussets are flat plates made up of a quasi-isotropic lay-up T300/954-3. Shear clips are INVAR-36 angle brackets. Joints using gussets and clips are much lighter than those using metallic plugs. Square tubes were preferred over circular ones in order to be able to use gussets and clips, thus resulting in a lighter weight structure. Two typical gusseted joints used by the ISIM baseline structure are depicted in Figures 5(a) and $5(\mathrm{~b})$, a diagonal joint and a K-Joint. A diagonal joint is one in which a member is connected in between two 
members of a plug joint using a pair of gussets. Two members are connected to a continuous member by means of a K-Joint.

Gussets provide good load paths for transfer of loads between the tubes in the plane of the gussets. Shear clips transmit transverse shear or out-of-plane forces between two members. Gussets do not provide a good load path for this component of force, which may induce high peel stresses at or near the gusset bonded joints and increases the risk of delamination. Shear clips may be eliminated at a joint only if the transverse shear forces are low enough, such that gussets can safely carry them.

It is important to use two gussets per joint, one on each of the opposite sides of a tube to maintain required stiffness and strength. Another prerequisite to achieve a structurally sound gusset joint is to tie only members that lie in a single primary plane, where a primary plane is defined as being parallel to one of the sides of a tube. Figure 5(c) illustrates an inferior joint, which is missing a gusset because it attempts to connect tubes that lie in two different primary planes. ISIM baseline structure avoids use of these weaker types of joints. Gussets need to have a minimum area based on stress analysis and should avoid stress concentrating features in view of the brittle nature of fiber reinforced composites. Extensive use of flat plate gussets requires all primary tubular members of the ISIM structure to lie in one of three primary planes. Tube connected by gussets cannot be at a compound angle to each other.
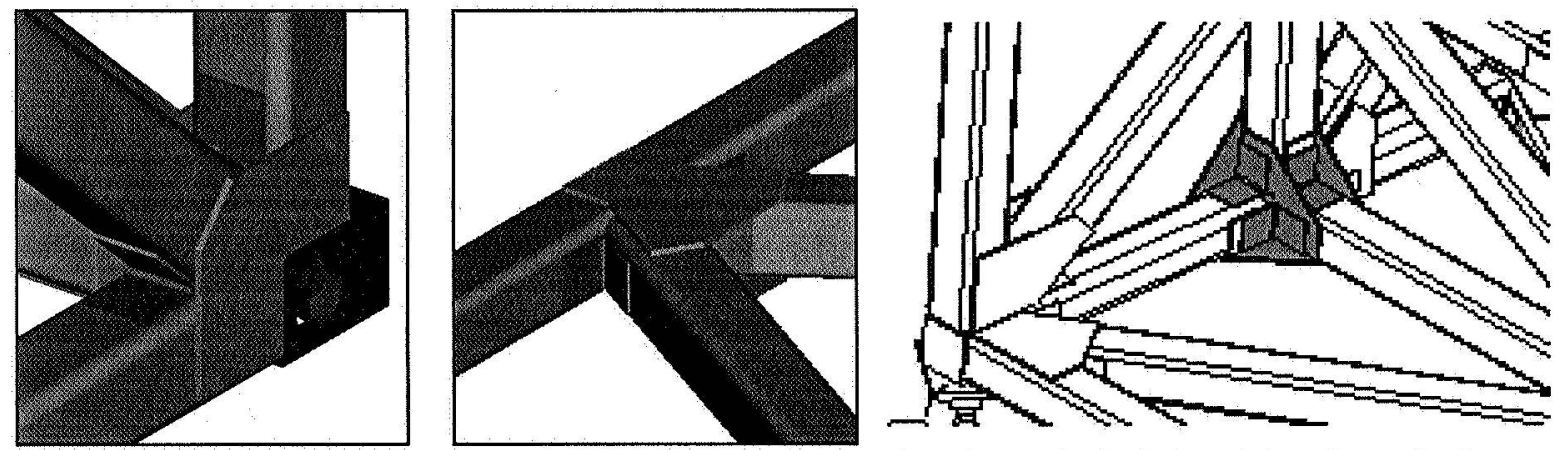

Figure 5: Joints using gussets and clips: (a) Diagonal Joint, (b) K-Joint, (c) Joint missing a critical gusset caused by trying to join members in more than one plane at the same location (not used by the baseline ISIM structure).

\subsection{Evolution of the Primary Structure and the Kinematic Mounts}

An extensive structure lay out trade study was undertaken during the early concept development phase considering over 100 different configurations. Figure 6 shows only a few of the structure lay-outs that were evaluated in order to arrive at an optimal structure topology to meet stiffness and strength requirements given the challenging accommodation and mounting constraints. Finite element analysis (FEA) played a significant role in assessing normal modes response of the structure during the lay out development process.

A significant determinant of the structure lay out and efficiency is the type, location, and orientation of the kinematic mounts. Different possibilities were negotiated with the telescope structure team. Based on load path considerations and FEA results, the significance of a lateral (V2) constraint at the front (+V3) end of ISIM was established. (V1-V2-V3 coordinate system is shown in Figure 4.) This constraint provides an essential torsional stiffness about the V3 axis provided that its load center is located at or close to the ISIM center of gravity. This idea evolved to the split bipod (two monopods) design as shown in Figs. 6 (e)-(f) and finally converged to the design shown in the baseline structure of Figure 4 . The monopods are attached to the $\pm \mathrm{V} 2$ sides of the front frame instead of the bottom deck. In this arrangement, the monopods provide a greater V2 stiffness owing to the reduced angle between their center lines and the V2 axis. Furthermore, the increased length of the monopods results in a more kinematic set of mounts. At the $-\mathrm{V} 3$ corners, two bipods are located and oriented for maximum structural efficiency. 


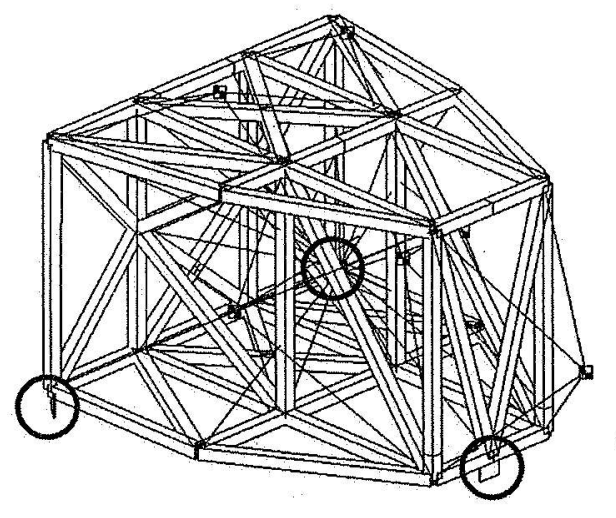

(a)

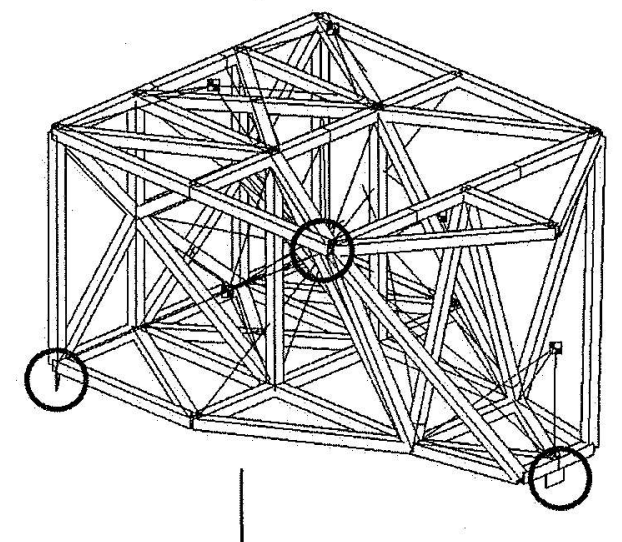

(c)

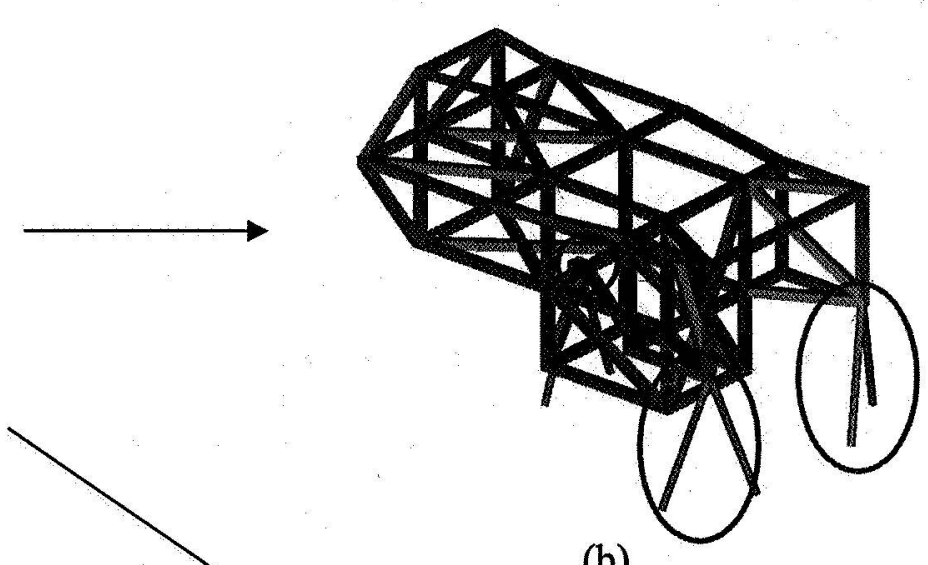

(b)

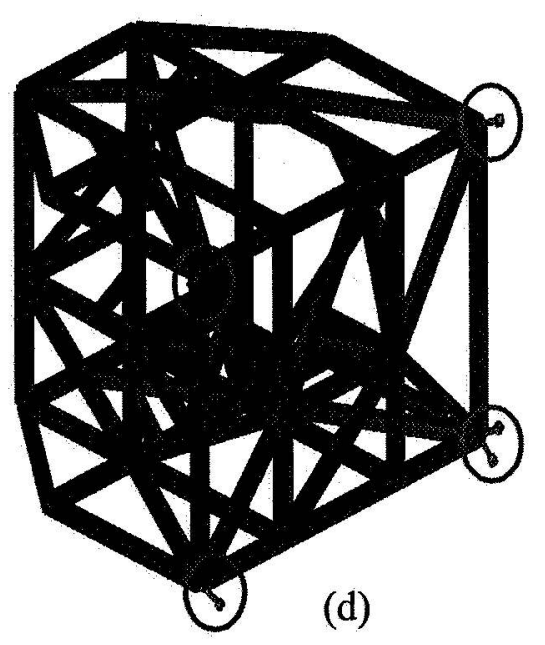

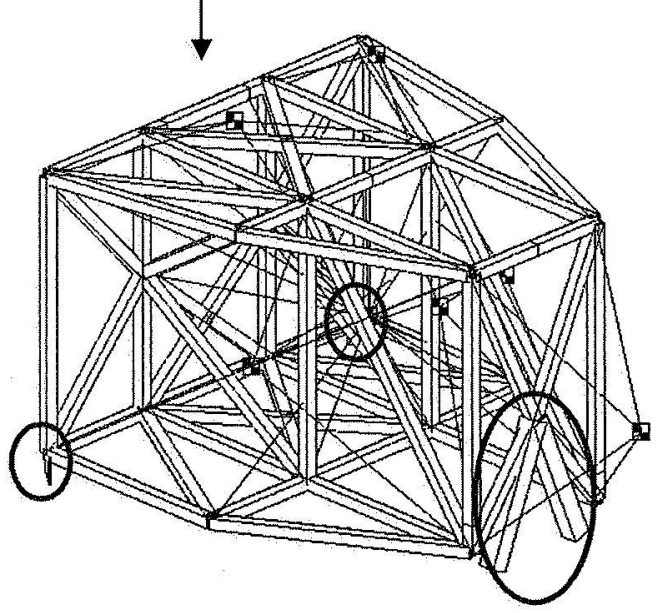

(e)

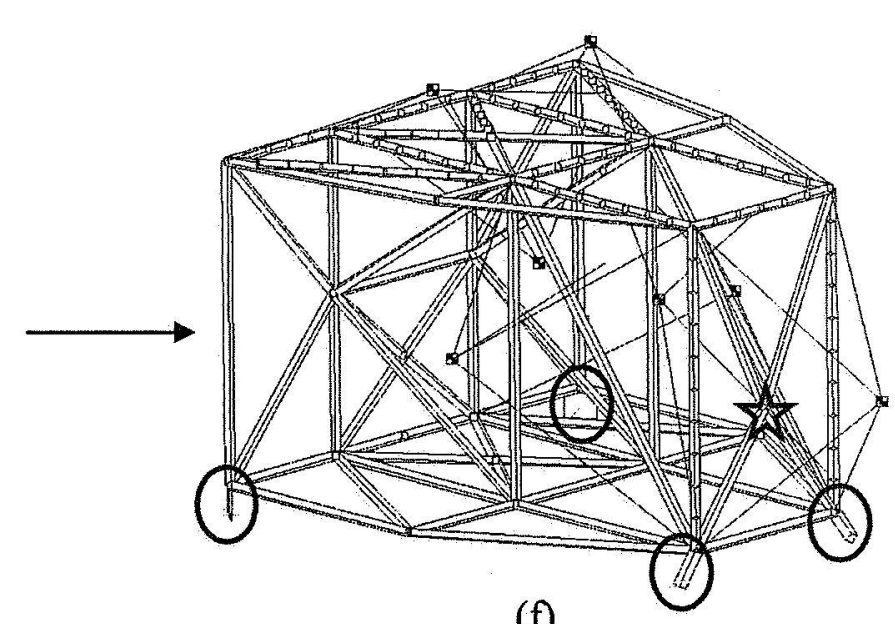

(f)

Figure 6: Selected views showing evolution of the ISIM primary structure configuration. Kinematic mounts are circled in red. 


\section{FINITE ELEMENT MODELS}

ISIM maintains two structural finite element models (FEM) of the overall integrated ISIM: (1) a loads and dynamics model and (2) a distortion model. These models are shown in Figure 7.

\subsection{Loads and Dynamics Model}

The loads and dynamics model represents the overall stiffness of ISIM structure accurately by using bar elements for the primary structure members and the kinematic mounts. Several different representations of the science instruments are used depending on the type of analysis. The simplest approach includes reduced representations using mass and bar elements tuned to meet the hard mounted fundamental frequency requirement of the instrument. Detailed models of the science instruments are included for coupled loads analysis either as physical or reduced dynamic (Craig-Bampton) models. The loads and dynamics FEM is used to predict the normal modes response of ISIM, to recover primary structure reactions under design limit loads, and for coupled loads analysis. Because of its simplicity and ease with which it can be modified, this model has also been extensively used in concept and trade studies.

\subsection{Distortion Model}

The distortion model is a high fidelity representation of the ISIM structure and the science instruments. The ISIM structure is modeled using solid elements and includes representations of tubes, gussets, clips, metal fittings, and adhesive bond lines. Detailed physical models of the science instruments are included in the distortion model. The ISIM distortion model is used for: distortion analysis under thermal and gravity loading, joint loads determination under cryogenic loading for stress analysis, and normal modes analysis to cross-check the loads and dynamics model.

(a)

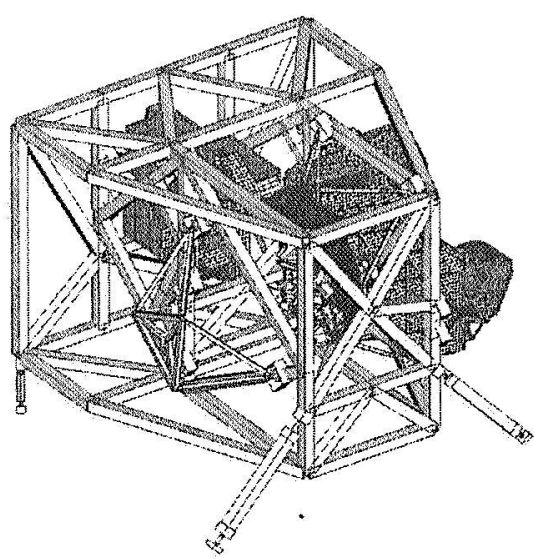

(b)

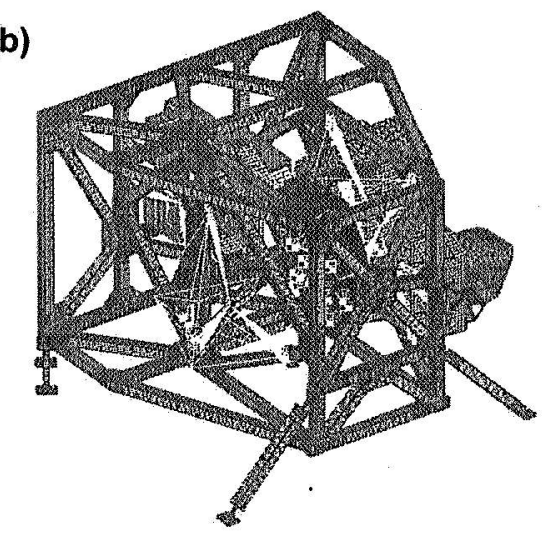

Figure 7: ISIM structural finite element models: (a) loads and dynamics model and (b) distortion model. Detailed physical models of the science instruments are shown in both models. 


\begin{tabular}{|c|c|c|c|c|c|c|c|}
\hline \multicolumn{8}{|c|}{ Mass Participation (\%) } \\
\hline$(\mathrm{Hz})$ & $\mathbf{X}$ & $\mathbf{Y}$ & $\mathbf{z}$ & $R X$ & RY & $\mathbf{R Z}$ & notes \\
\hline 27.7 & 0.0 & 0.1 & 64.3 & 0.4 & 58.7 & 0.3 & Major V3 \\
\hline 32.6 & 0.6 & 0.1 & $\overline{11.0}$ & 10.2 & 8.6 & 0.1 & Minor V3 \\
\hline 33.9 & 0.0 & 74.0 & 0.1 & 19.9 & 0.3 & 51.9 & V2 + V3 Torsional \\
\hline 38.4 & 7.2 & 2.7 & 0.6 & 1.8 & 0.6 & 21.9 & $V_{1}+V_{3}$ Torsional \\
\hline 39.0 & 22.0 & 0.4 & 0.1 & 0.2 & 0.0 & 1.3 & V1 due to Local SI \\
\hline
\end{tabular}
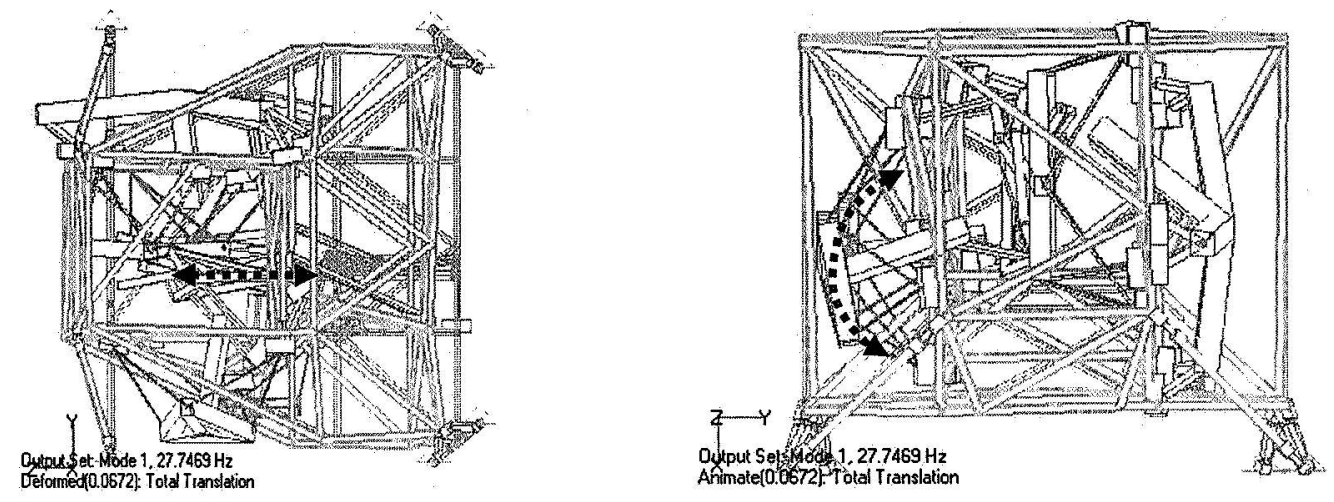

Figure 8: Baseline Structure Normal Modes Analysis Results: (a) Frequencies, mass participation and mode shape descriptions, (b) Views of the fundamental mode shape with arrows indicating major deformation in the V3 axis and local V2 rotation participation in the FGS area.
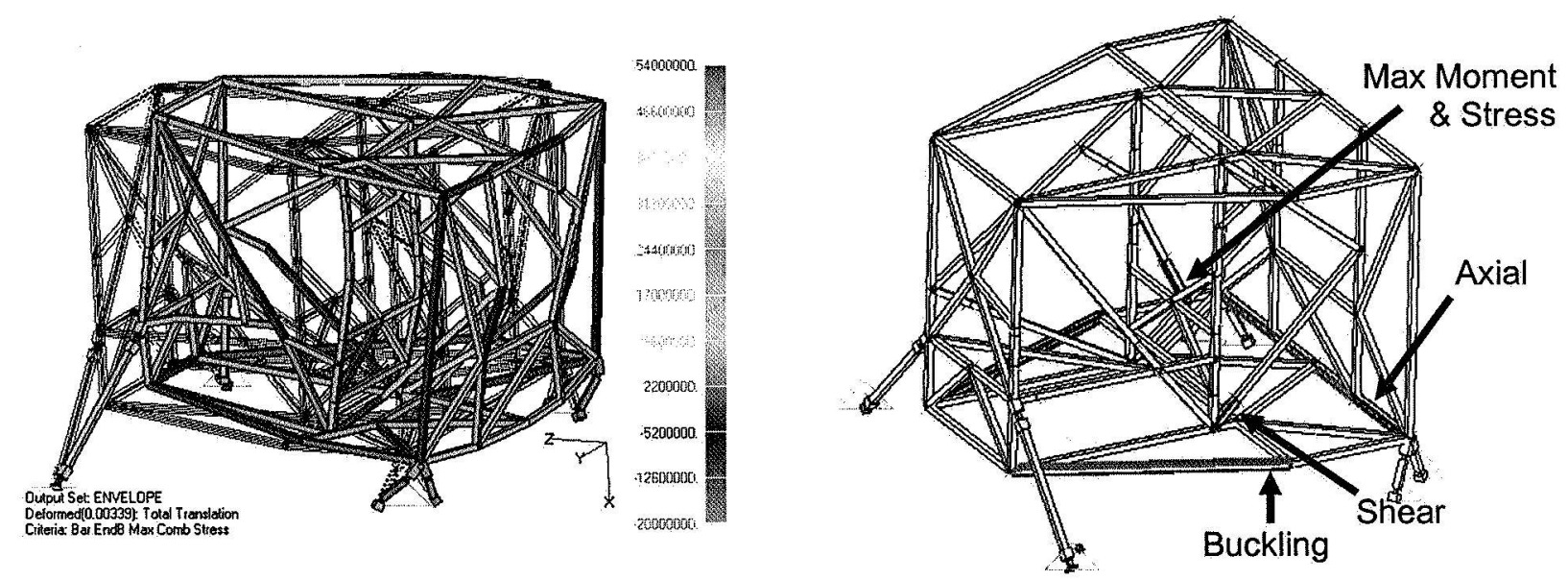

Primary Structure Bar Element ENVELOPING Limit Reactions (N, N.m)

\begin{tabular}{|c|c|c|c|c|c|c|c|c|c|c|c|}
\hline element & & MA1 & MA2 & MB1 & MB2 & v1 & V2 & $\mathbf{P}$ & $T$ & stress & buckling \\
\hline ID & worst & 1021 & 888 & 1197 & 892 & 11898 & 5459 & 47888 & 282 & MS & MS \\
\hline 158202 & Stress & 205 & 834 & 293 & 627 & 731 & 4538 & 20568 & 61 & 2.6 & 3.7 \\
\hline 162306 & Buckling & 70 & 135 & 218 & 88 & 181 & 142 & 25908 & 8 & 5.9 & 3.1 \\
\hline 106108 & Axial & 198 & 143 & 91 & 130 & 501 & 412 & 47888 & 8 & 2.8 & 7.9 \\
\hline 202210 & Shear & 752 & 402 & 430 & 275 & 11898 & 4842 & 4499 & 138 & 3.4 & 20.4 \\
\hline 140148 & Moment & 54 & 393 & 1197 & 221 & 3982 & 1959 & 1442 & 114 & 10.4 & +large \\
\hline
\end{tabular}

Figure 9: Baseline Structure Stress and Margin of Safety (MS) Summary under Launch Loads. (a) Max Stresses (MPa) and deformed shape under enveloping launch cases (b) Structural elements with critical failure modes highlighted (c) Summary of worst case reaction forces and $\min$ MS. 


\section{BASELINE STRUCTURE PERFORMANCE PREDICTIONS}

\subsection{Normal Modes \& Fundamental Frequency}

The fundamental frequency of the baseline structure as predicted by the Loads and Dynamics FEM is 27.7 $\mathrm{Hz}$. This meets the minimum frequency requirement of $25 \mathrm{~Hz}$ with margin. Figure 8(a) lists the first five natural frequencies and mass participation percentages along with a description of the mode shapes. Figure $8(b)$ shows deformed shape plots of the fundamental mode at $27.7 \mathrm{~Hz}$.

\subsection{Stress Analysis and Strength Margins of Safety (MS)}

The loads and dynamics FEM is used to predict the reactions of primary structure members under launch design limit loads. Figure 9(a) shows enveloping maximum stresses of the tube members. Strength Margins of Safety is defined as MS=(Allowable Stress or Force) / (Applied Stress or Force)*FS]-1. Minimum MS is calculated for the primary members using predicted maximum stresses and material allowables as well as using maximum predicted forces and column buckling strength of the members as listed in Figure 9(c). Figure 9(b) highlights members that are critical under different failure modes such as maximum bending, maximum shear, and buckling. MS for the primary members are positive thus meeting the strength requirement.

Gusset joints of the structure are also evaluated for strength under launch loads using a top level stress analysis approach based on classical hand calculations. Launch reactions obtained from loads FEM are used. Figure 10 summarizes the results of this analysis and highlights the members with critical gussets. All MS are positive for the gussets thus complying with the launch strength requirement.

A more in depth stress analysis of the critical structural components including bonded joints is in progress. Detailed stress analysis models are prepared and run under launch as well as cool-down load cases. Details of these analyses are not presented here, as they are not the focus of this paper.
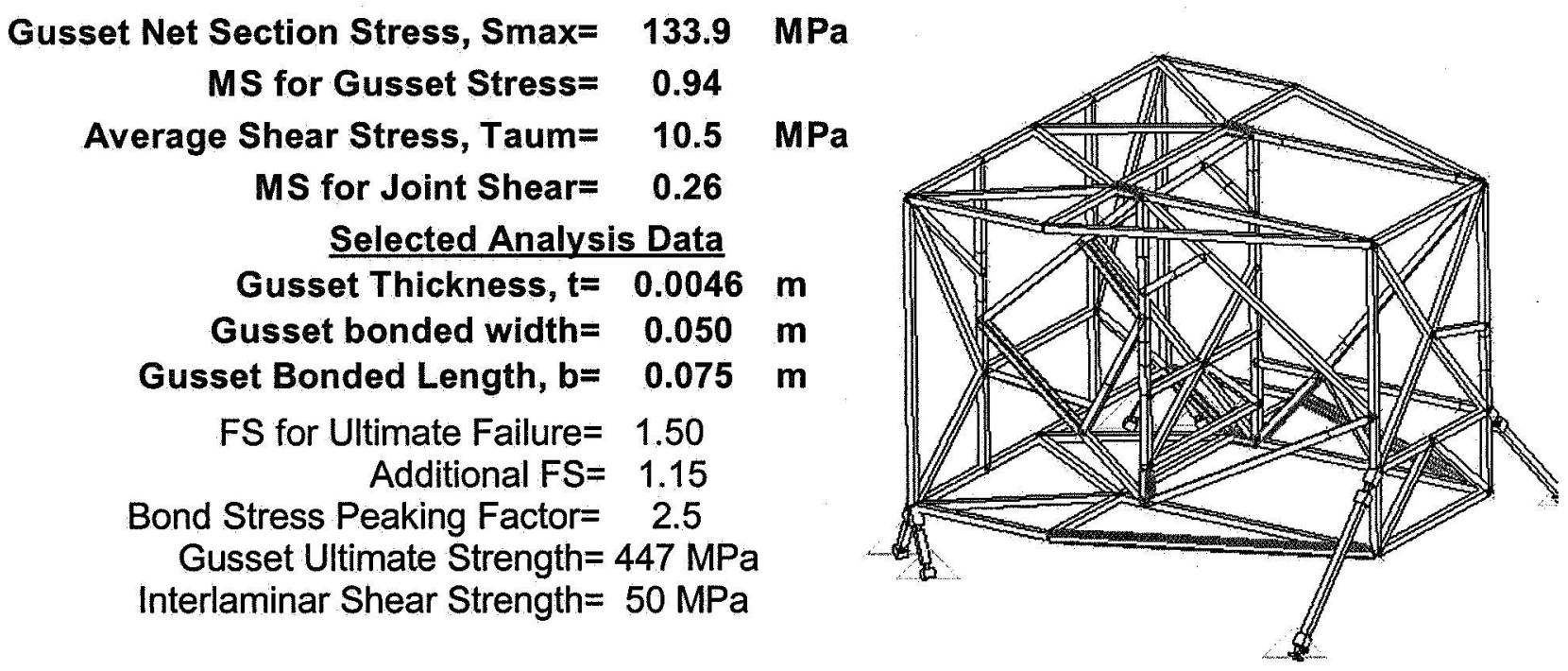

Figure 10: Summary of gusset joints top level stress analysis based on reactions predicted by loads and dynamics FEM. Critical gussets are highlighted. 


\subsection{Distortion Analysis}

The distortion FEM was used to predict ISIM structure distortion performance under thermal and gravity loading with respect to both ground to orbit alignment and operational stability requirements. For ground to orbit performance, the ISIM structure meets requirements for science instrument interface pad motions, science instrument interface pad-to-pad relative motions, and allowable loads at the telescope interface. For operational stability, the ISIM structure meets requirements for science instrument interface motions and allowable loads at the telescope interface. Details of these analyses are not presented here, as they are not the focus of this paper.

\section{SUMMARY}

This paper has provided an overview of the design challenges and resulting structural evolution to the current baseline concept for the JWST-ISIM structure. The combination of stiffness and distortion requirements with mass limitations led to the selection of a bonded composite frame construction for the primary structure. Kinematic mount design was tailored to maximize natural frequency while limiting secondary interface loads. Finite element models used to predict structural performance were described along with baseline performance predictions. The baseline ISIM structure currently meets all key requirements and is in the detailed design phase of development.

\section{REFERENCES}

1. "An overview of the James Webb Space Telescope (JWST) project," Phillip A. Sabelhaus, Doug Campbell, Mark Clampin, John Decker, Matt Greenhouse, Alan Johns, Mike Menzel, Robert Smith, Pam Sullivan, Proc. SPIE Vol. 5899, p. 241-254, UV/Optica1/IR Space Telescopes: Innovative Technologies and Concepts II, August 2005.

2. "The James Webb Space Telescope instrument suite layout: optical system engineering considerations for a large deployable space telescope" Brent J. Bos, Pamela S. Davila, Matthew Jurotich, Gurnie Hobbs, Paul A. Lightsey, James Contreras, Tony Whitman, Proc. SPIE Vol. 5487, p. 734-745, Optical, Infrared, and Millimeter Space Telescopes, October 2004.

3. "Design/analysis of the JWST ISIM bonded joints for survivability at cryogenic temperatures," Andrew Bartoszyk, John Johnston, Charles Kaprielian, Jonathan Kuhn, Cengiz Kunt, Benjamin Rodini, Daniel Young, Proc. SPIE Vol. 5868, p. 171-180, Optical Materials and Structures Technologies II, August 2005. 

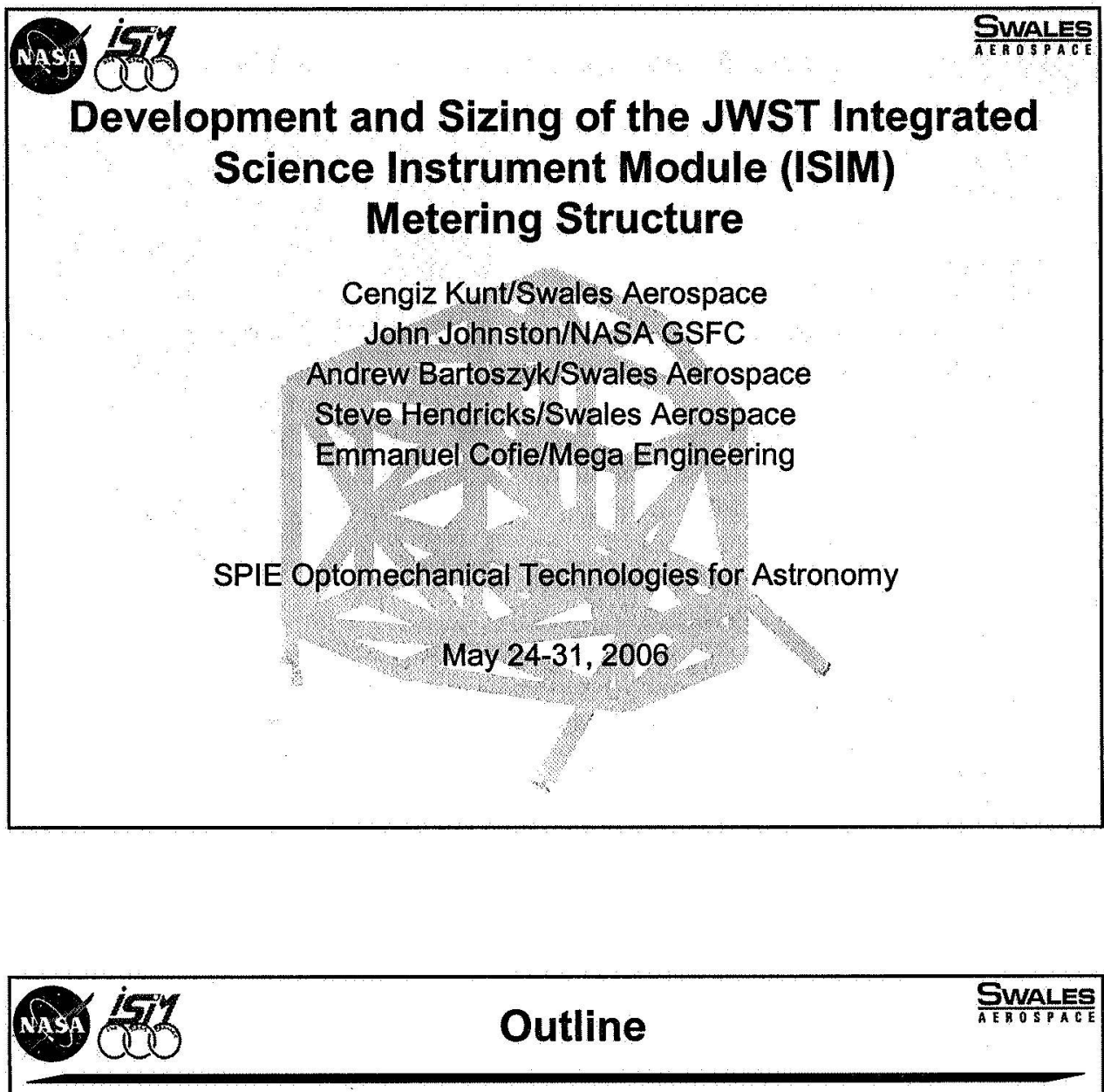

- Introduction

- ISIM Structural Requirements \& Challenges

- Description \& Evolution of the Primary Structure

- Finite Element Models

- Performance Predictions

- Normal Modes

- Structural Integrity

- Distortion

- Summary 


\begin{tabular}{|c|c|}
\hline Jan & Nebb Space Telescope \\
\hline $\begin{array}{l}\text { Milission Objective } \\
\text { - Study the origin and evolu } \\
\text { planetary systems } \\
\text { - Optimized for infrar } \\
\text { Organization } \\
\text { - Mission Lead: Goddard S } \\
\text { = Intemational collaboration } \\
\text { - Prime Contractor: Northro } \\
\text { - Instruments: } \\
\text { - Near Infrared Cam } \\
\text { - Near Infrared Spec } \\
\text { - Mid-Infrared Instrur } \\
\text { - Fine Guidance Sen } \\
\text { - Operations: Space Teles }\end{array}$ & 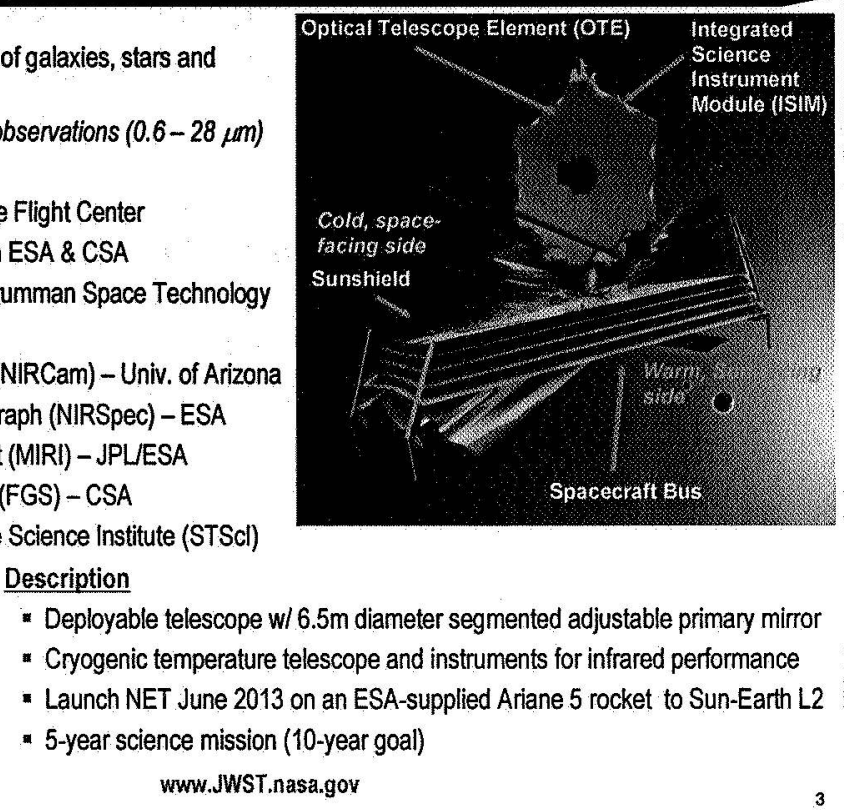 \\
\hline
\end{tabular}

AST JWO JWS Architecture

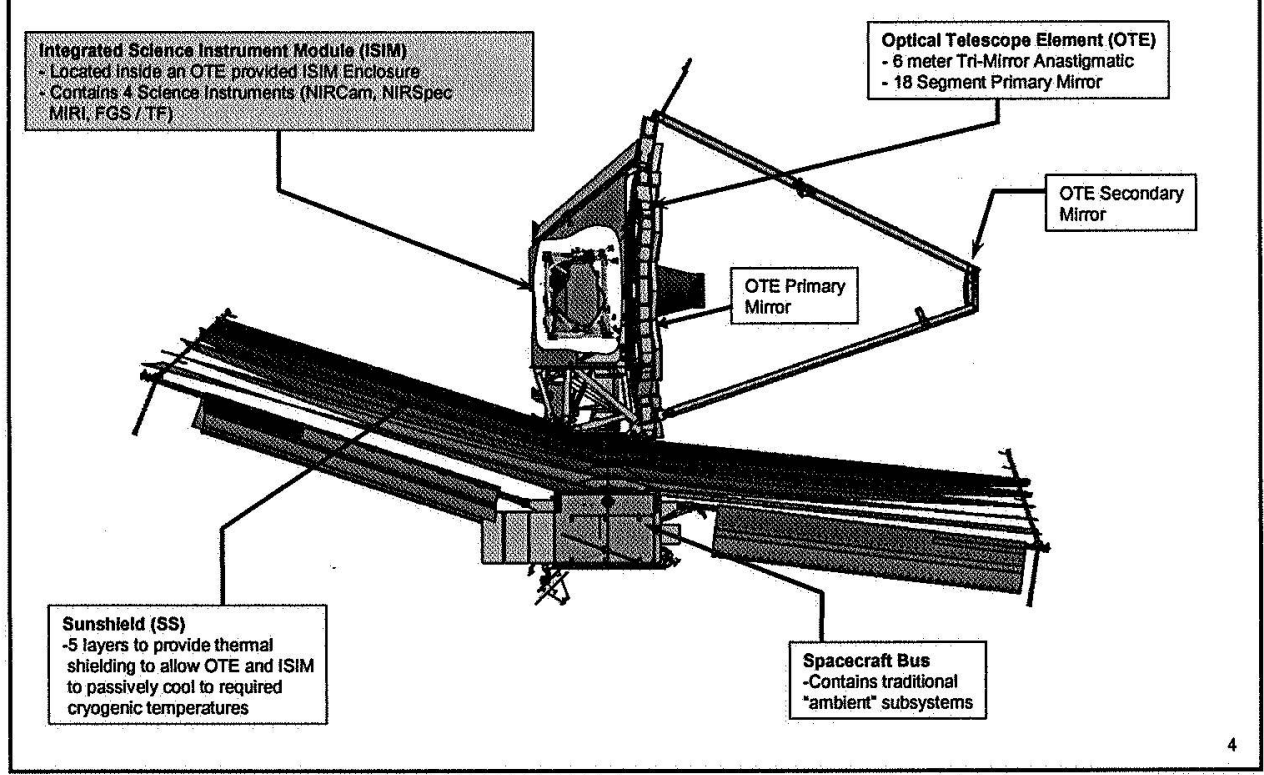




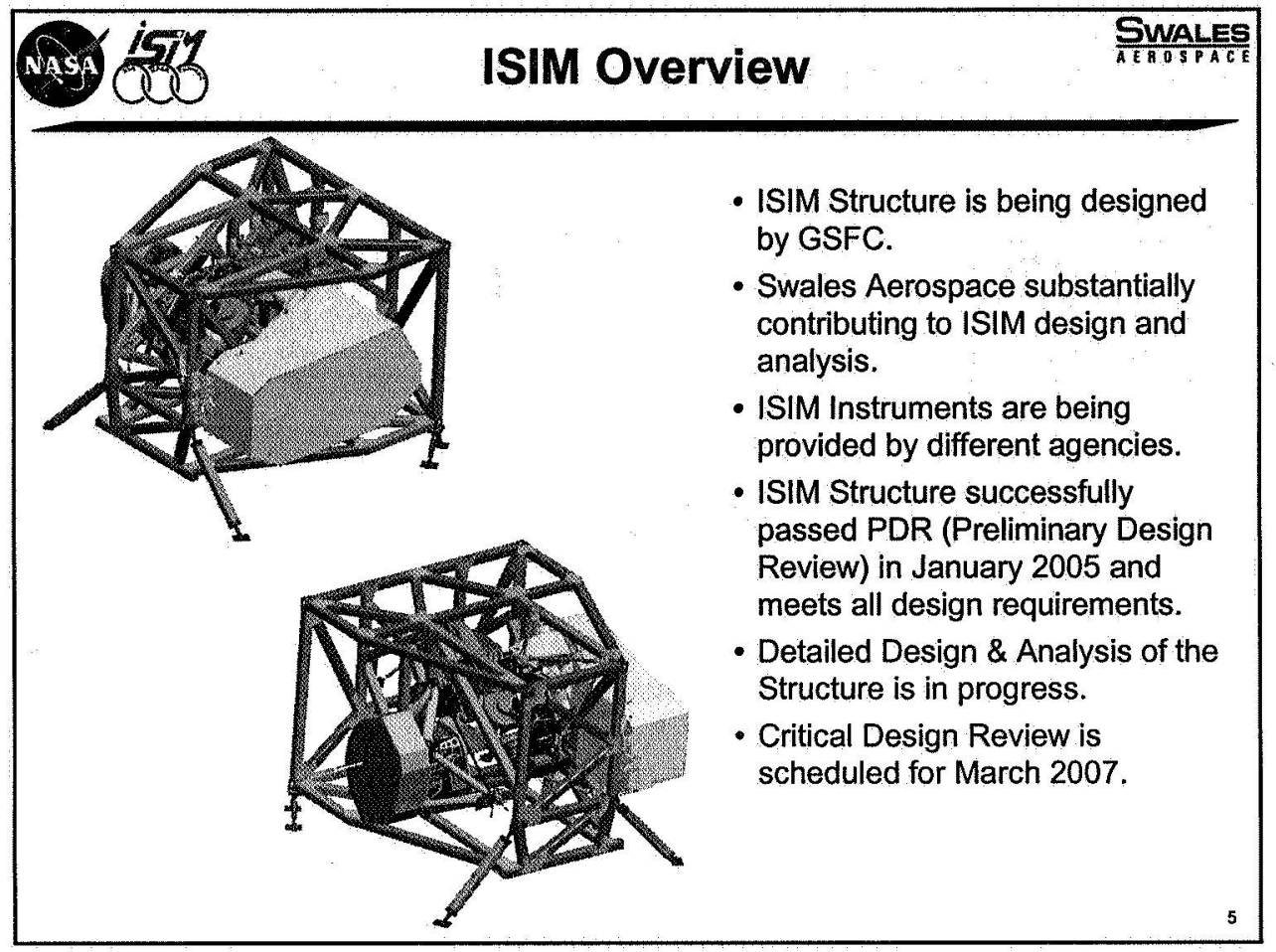

\begin{tabular}{ccc}
\hline ISIM Structure Critical Requirements & $\begin{array}{c}\text { SWALES } \\
\text { \& Majospat }\end{array}$ \\
\hline
\end{tabular}

- Scientific Instrument (SI) Accommodations - Volumes \& Access

- SI \& OTE Interfaces

- Total Supported Mass of $1140 \mathrm{~kg}$

- Structure Mass Allocation of $300 \mathrm{~kg}$

- Minimum Fundamental Frequency $+25 \mathrm{~Hz}$ with margin

- Structural Integrity under Launch

- Thermal Survivability

- Survival Temp $=22 \mathrm{~K}$

- Operating Temp $=32 \mathrm{~K}$

- Distortion Performance

- Cool-Down to $32 \mathrm{~K}$

- Operational Stability at $32 \mathrm{~K}$

Design a Structure that satisfies these Constraints and meets the following Challenging Requirements:

\section{Challenge\#1}

Launch Stiffness \& Strength

Focus of this Presentation

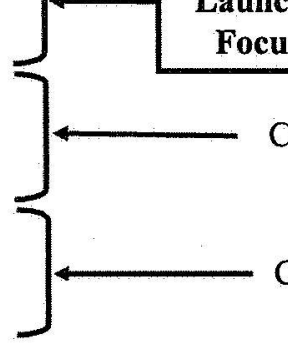

Challenge\#2

Challenge\#3 


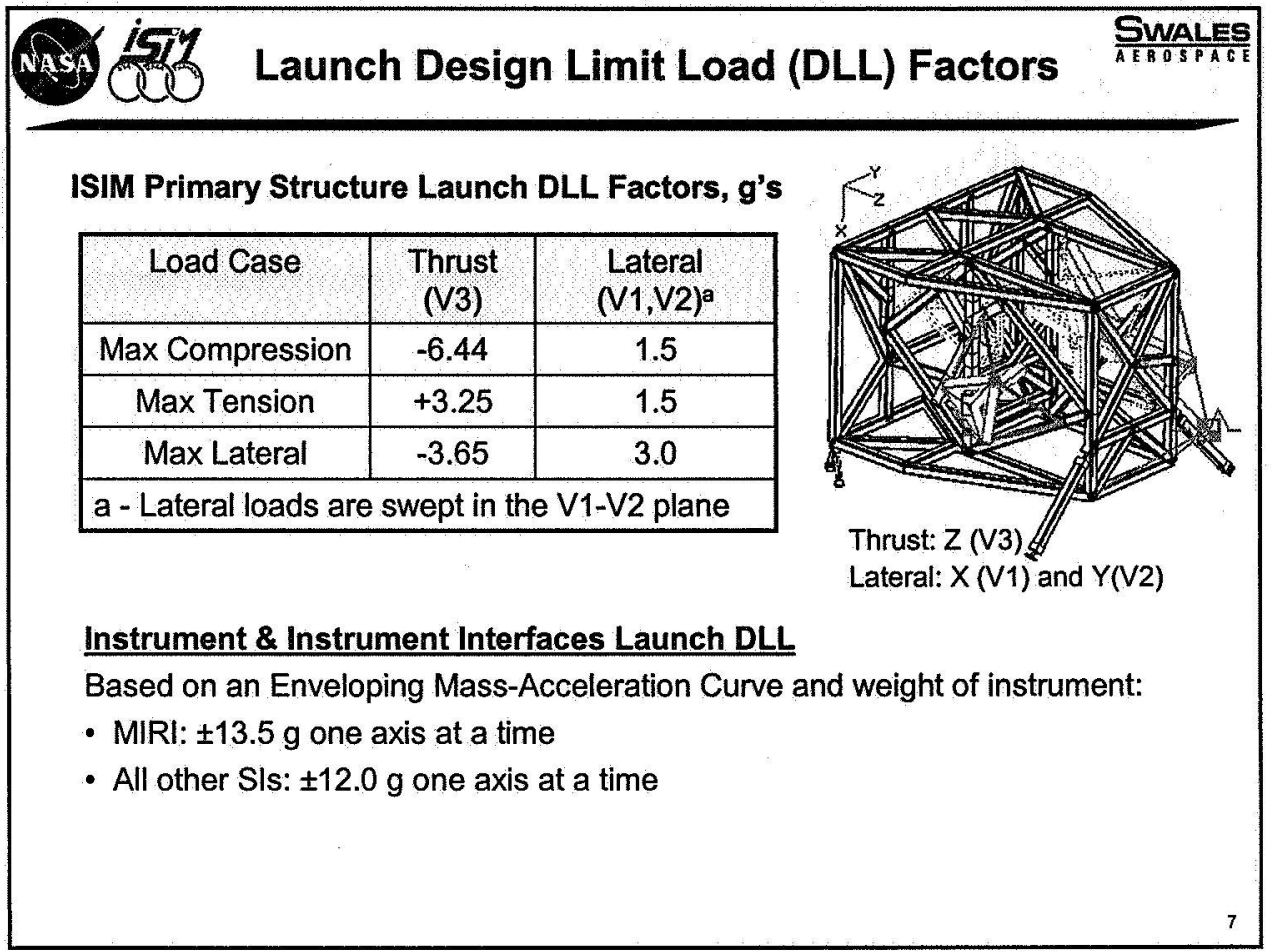

Factors of Safety (FS)
for Flight Hardware Strength Analysis
\begin{tabular}{|c|c|c|c|}
\hline Type of Structure & Qualification by & \multicolumn{2}{|c|}{ FS } \\
\cline { 2 - 4 } & ultimate & yield \\
\hline Metallic & Analysis \& Test & 1.40 & 1.25 \\
\cline { 2 - 4 } & Analysis only & 2.6 & 2.0 \\
\hline Mechanical Fastener & Analysis \& Test & 1.40 & 1.25 \\
\hline Composite Material & Analysis \& Test & 1.50 & - \\
\hline Adhesive & Analysis \& Test & 1.50 & 1.25 \\
\hline
\end{tabular}
Notes:
1 FS listed apply to both mechanically and thermally induced loads.
Strength Margin of Safety, MS= Allowable/(FS * Applied) - 1
2 Use of an additional fitting factor (typically 1.15) is at the discretion of the analyst.
3 For tension fasteners, use an FS of 1.0 on torque preload tension. Maintain a minimum
gapping FS of 1.25.
4 Localized yielding of adhesive that does not undermine performance is acceptable.




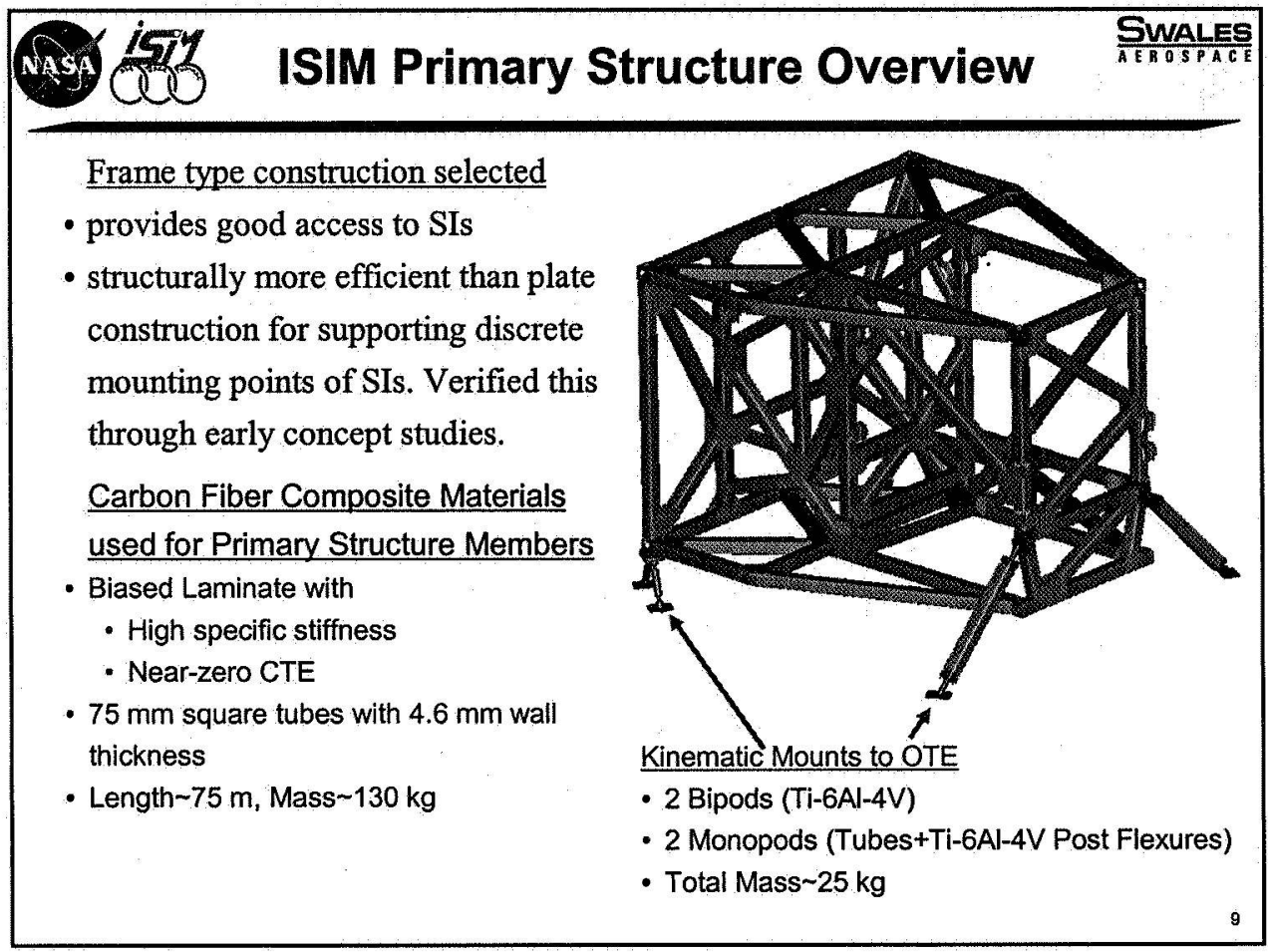

\section{Primary Structure Load Paths PWALES}

- Structure lay-out is close to a 3D truss but deviates from it due to need to have open bays for SI integration and stay-out zones

- Open bays are for

- NIRCam \& Light Cones

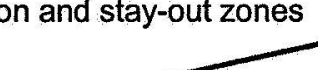

- FGS

- AOS stay-out zone

- Open bays stiffened through adjacent trusses and "wings."

- No removable members used to stiffen the open bays in view of distortion risk.

- All primary load lines intersect at joints.

- Trusses in different planes are staggered to simplify some joints, for example:

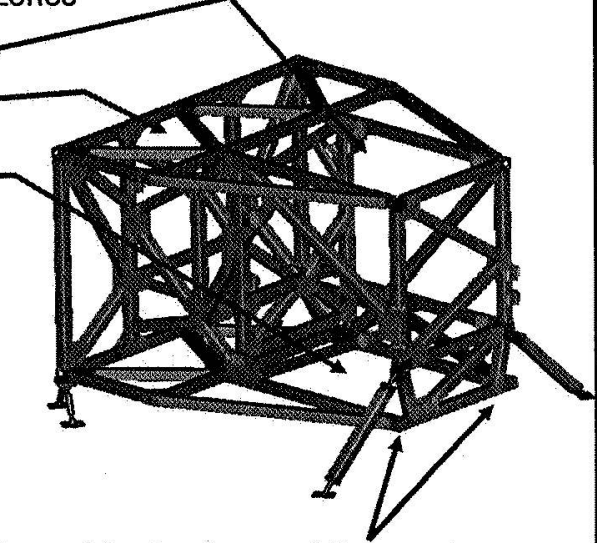

- with the removal of the dewar, plug fittings at the two lower $+\mathrm{V} 3$ corners are also removed and members properly offset and joined through lighter gussets and shear clips. 


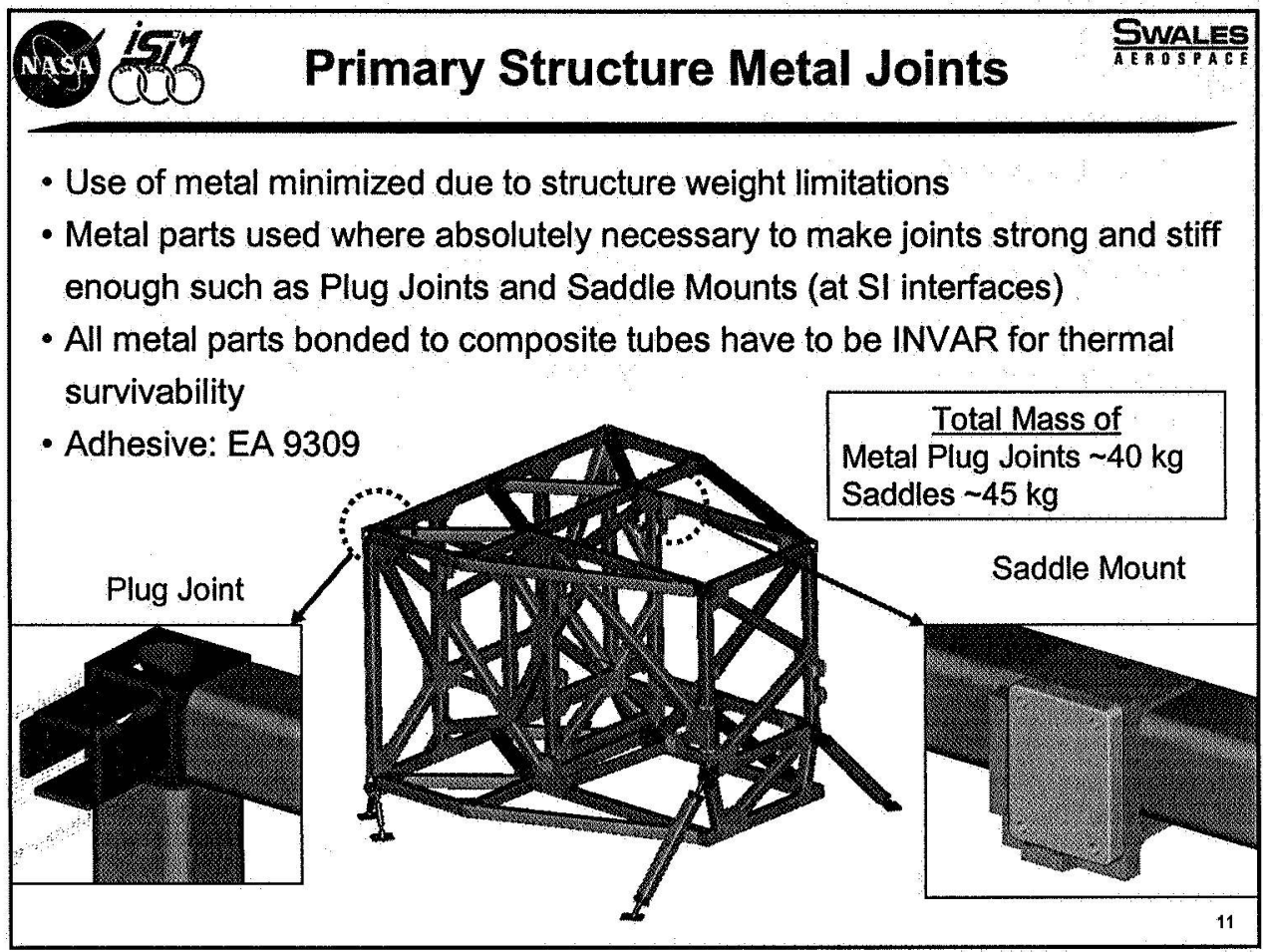

\section{NASA ISy Primary Structure Gusseted \& Clipped $\begin{gathered}\text { SWALES } \\ \text { Joints }\end{gathered}$}

- Square Tubes used to make light weight joints possible with gussets and shear clips

- Gussets and clips sized to result in joints with good strength provided that

- a pair of gussets and a pair of clips are used, and

- gussets are not notched to undermine the joint load paths

- Gussets: $4.5 \mathrm{~mm}$ thick QI (Quasi-Isotropic) Laminate

- Clips: $1.9 \mathrm{~mm}$ thick INVAR

- Adhesive: EA 9309

Joint missing a critical gusset

Caused by trying to join members in perpendicular planes at the same location. Not used by the baseline ISIM Structure

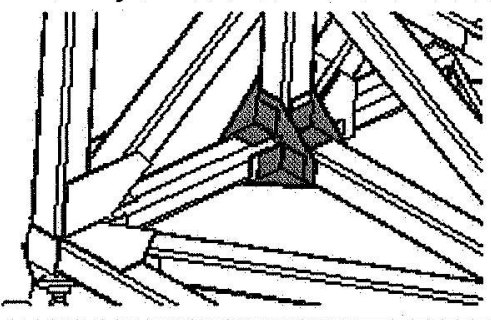

Total Mass of

Gussets $\sim 20 \mathrm{~kg}$ Shear Clips $\sim 10 \mathrm{~kg}$ Adhesive $2 \mathrm{~kg}$

Joints with good load paths 1) Diagonal Joint, 2) K-Joint
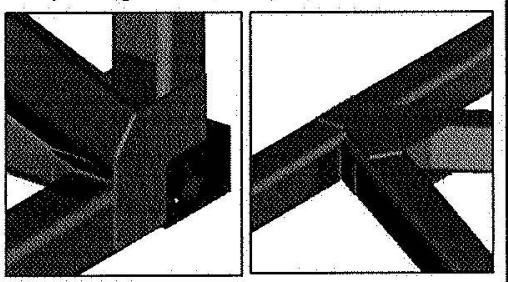


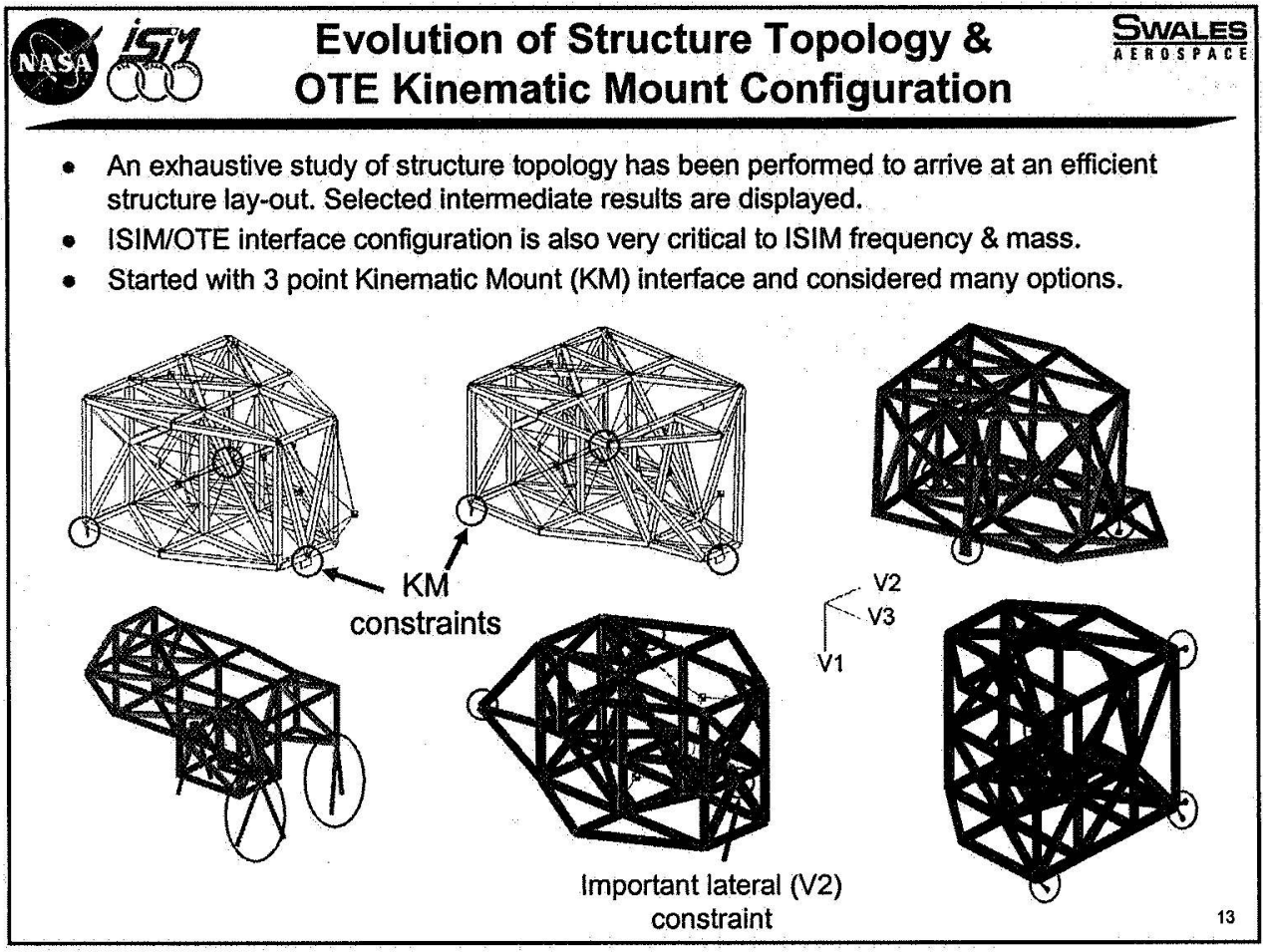

\section{ISI Arriving at the Final Structure Topology \& SWALES OTE Kinematic Mount Configuration}

- Found that a lateral (V2) constraint at the $+\mathrm{V} 3$ end is very effective

- if it is at or close to the projected CG of ISIM

- Because it provides an essential V3 torsional stiffness

- Finally evolved to a split Bipod (pair of Monopods) as shown below.

- At the $-\mathrm{V} 3$ end, two bipods are oriented optimally for maximum stiffness.

- The resulting structure topology is discussed in detail on the next slide.

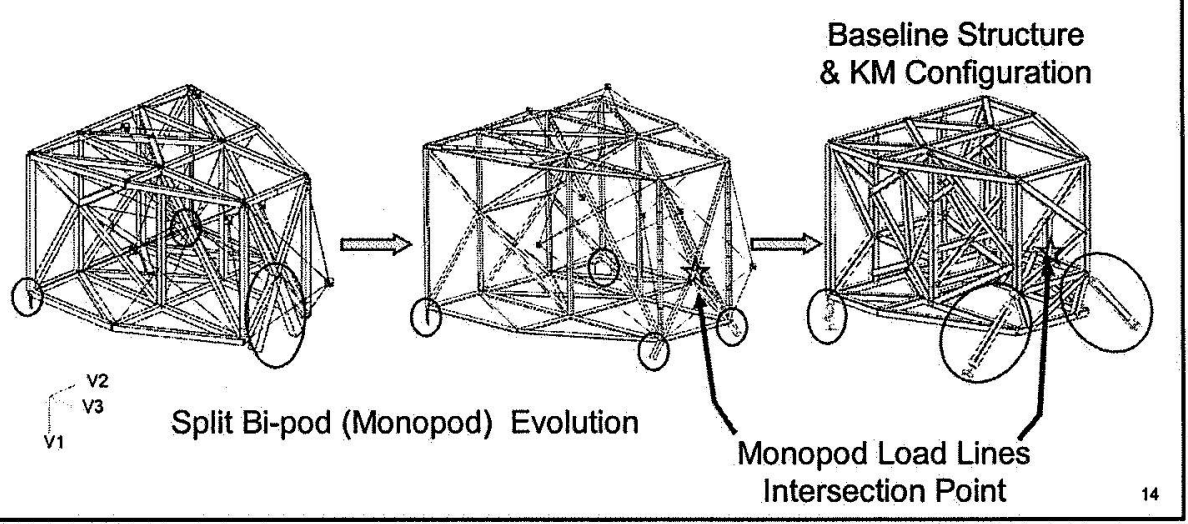




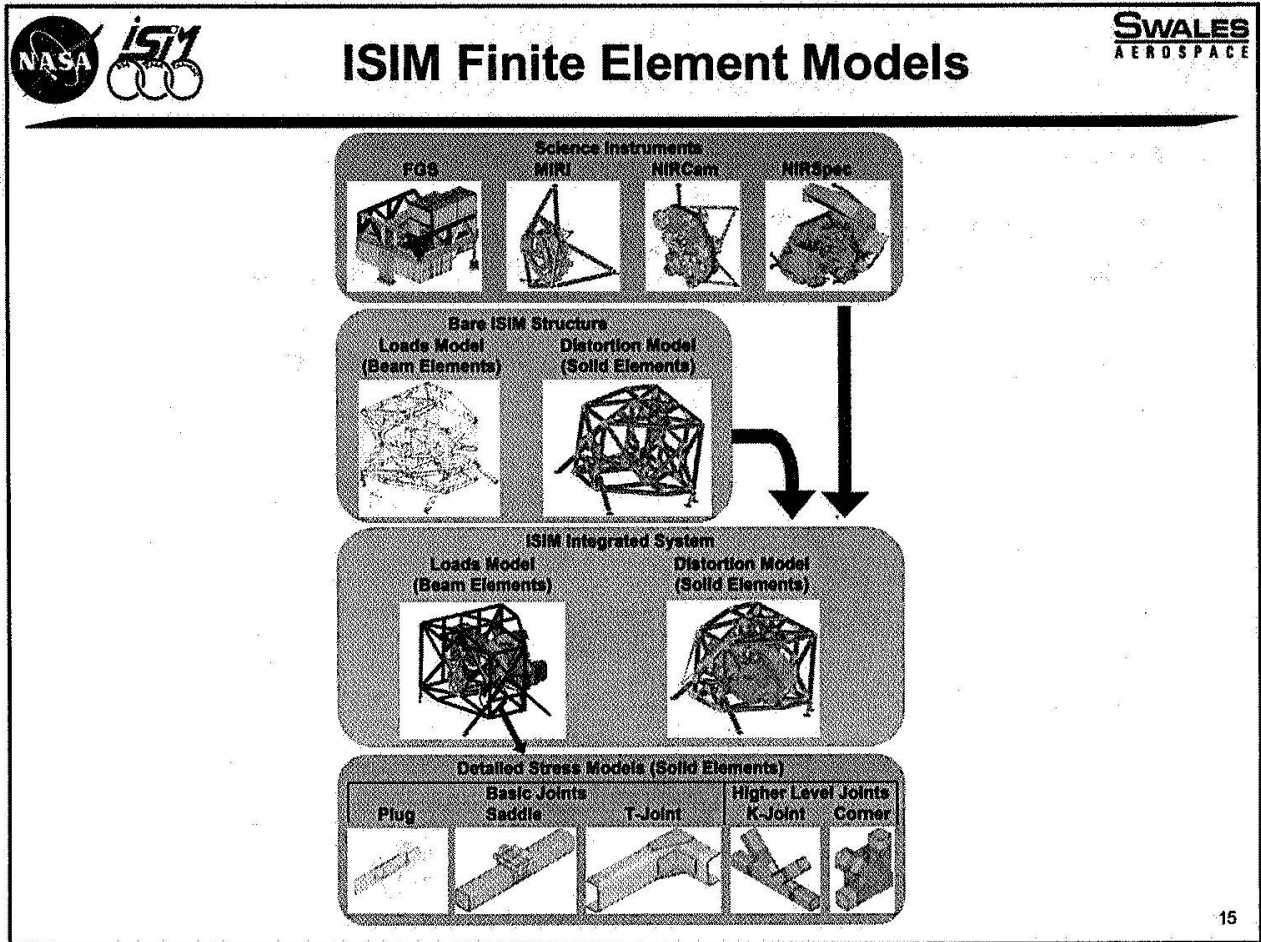

\section{(495) 157 ISIM Finite Element Models - cont.}

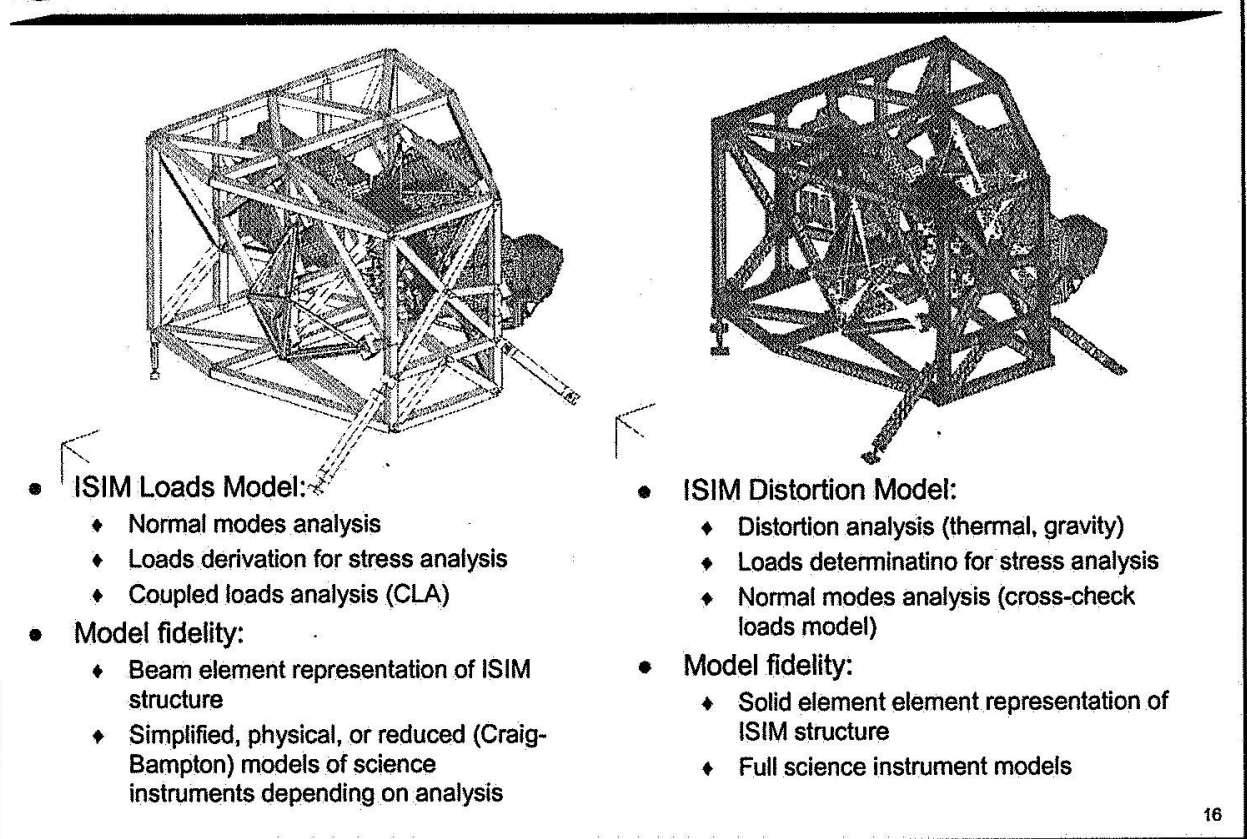




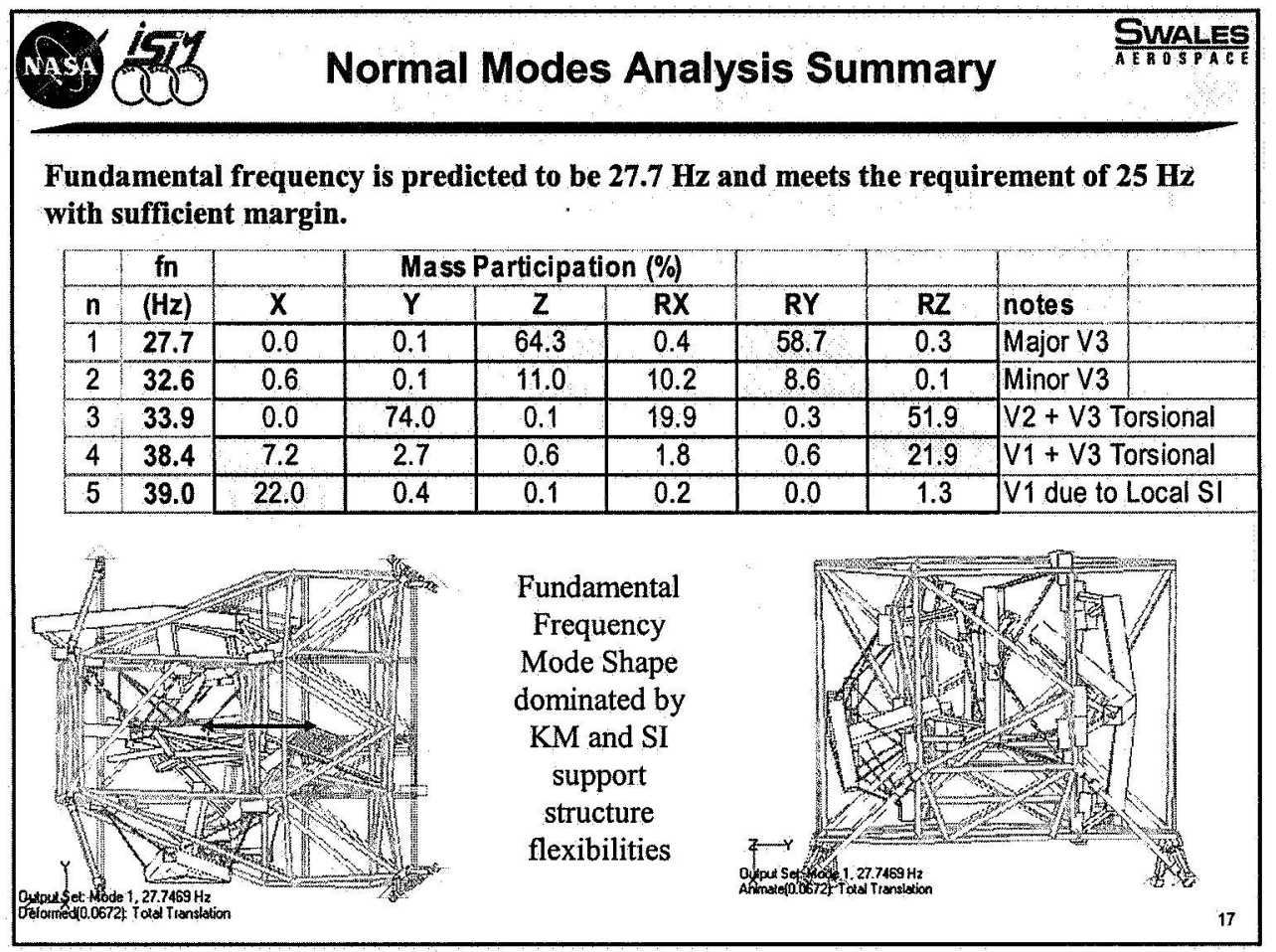

Maximum Deformations \& Stresses
Under Launch Loads

- Results shown for the envelope of all launch load cases

- Max deformation is under $3.5 \mathrm{~mm}$

- Max tube stress is $\sim 54 \mathrm{MPa}$ which is well under the allowable

Primary Tube Stress Contours (Pa) Under Enveloping Load Case Deformed \& Undeformed Shapes Shown

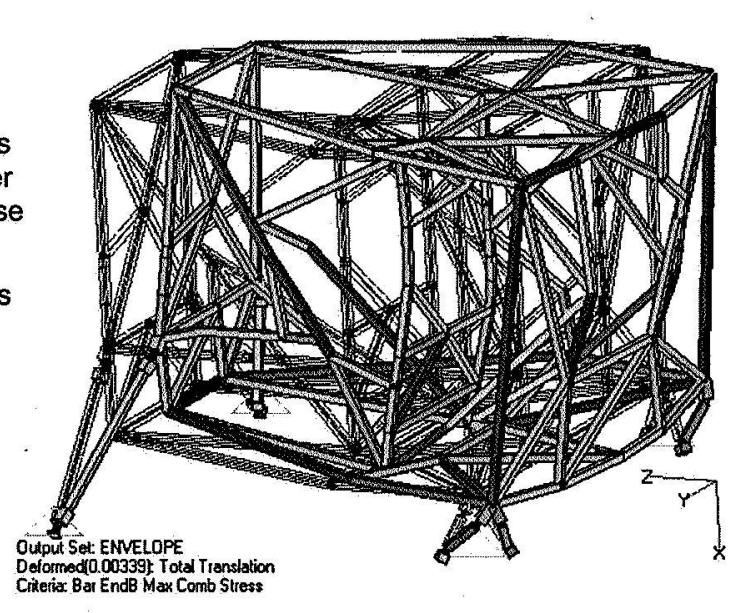

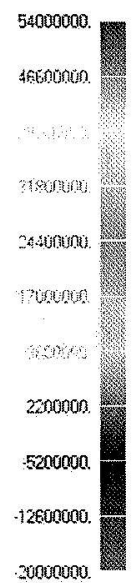




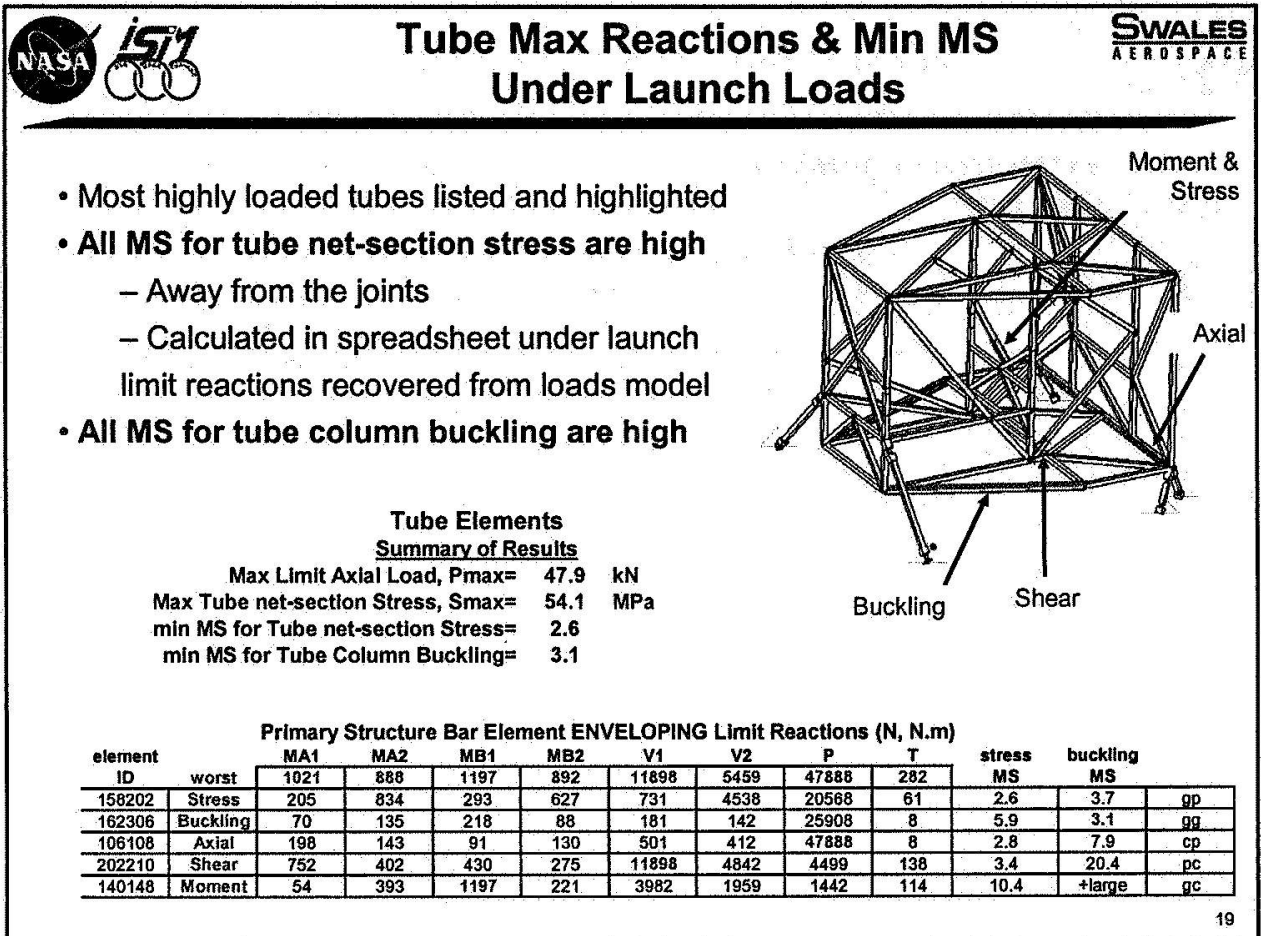

\section{ASA ISI Joint Reactions \& MS under Launch Loads SWALES Gussets}

- Joint reactions under launch loads are recovered from loads model. Selected results shown here for gussets.

- Stresses and MS are calculated by hand analysis for:

- Gusset net-section failure

- Gusset-tube bonded joint shear failure

- Summarized below and highlighted in the FEM plot
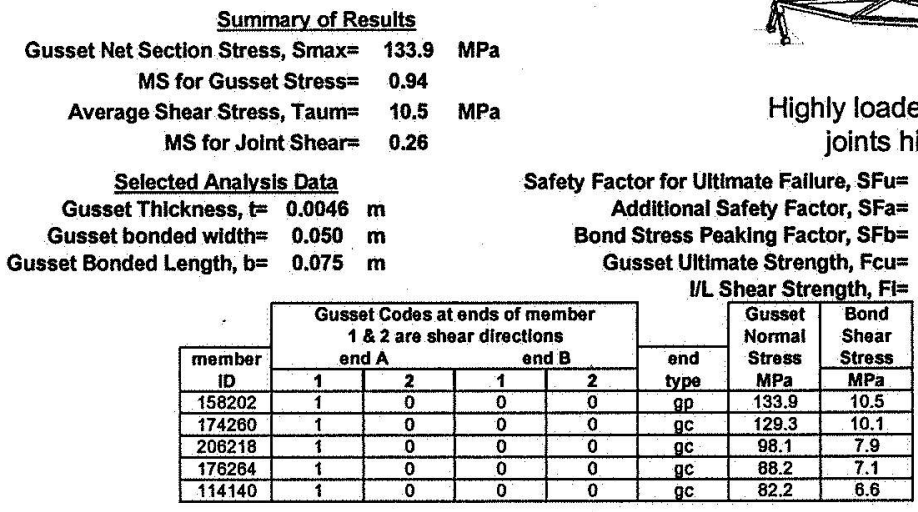

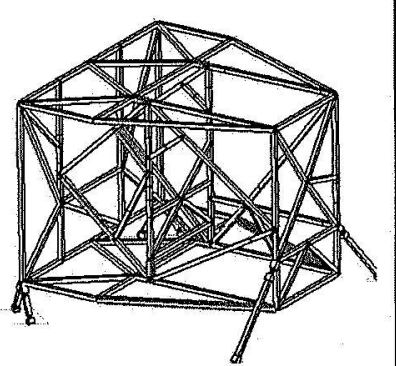

Highly loaded gusset-tube joints highlighted

Safety Factor for Ultimate Failure, SFu= $\quad 1.50$

Additional Safety Factor, SFa= $\quad \mathbf{1 . 1 5}$

Bond Stress Peaking Factor, $\mathbf{S F b}=2.50$

Gusset Ultimate Strength, Fcu= $\quad 447.0 \mathrm{MPa}$

$50.0 \mathrm{MPa}$ 


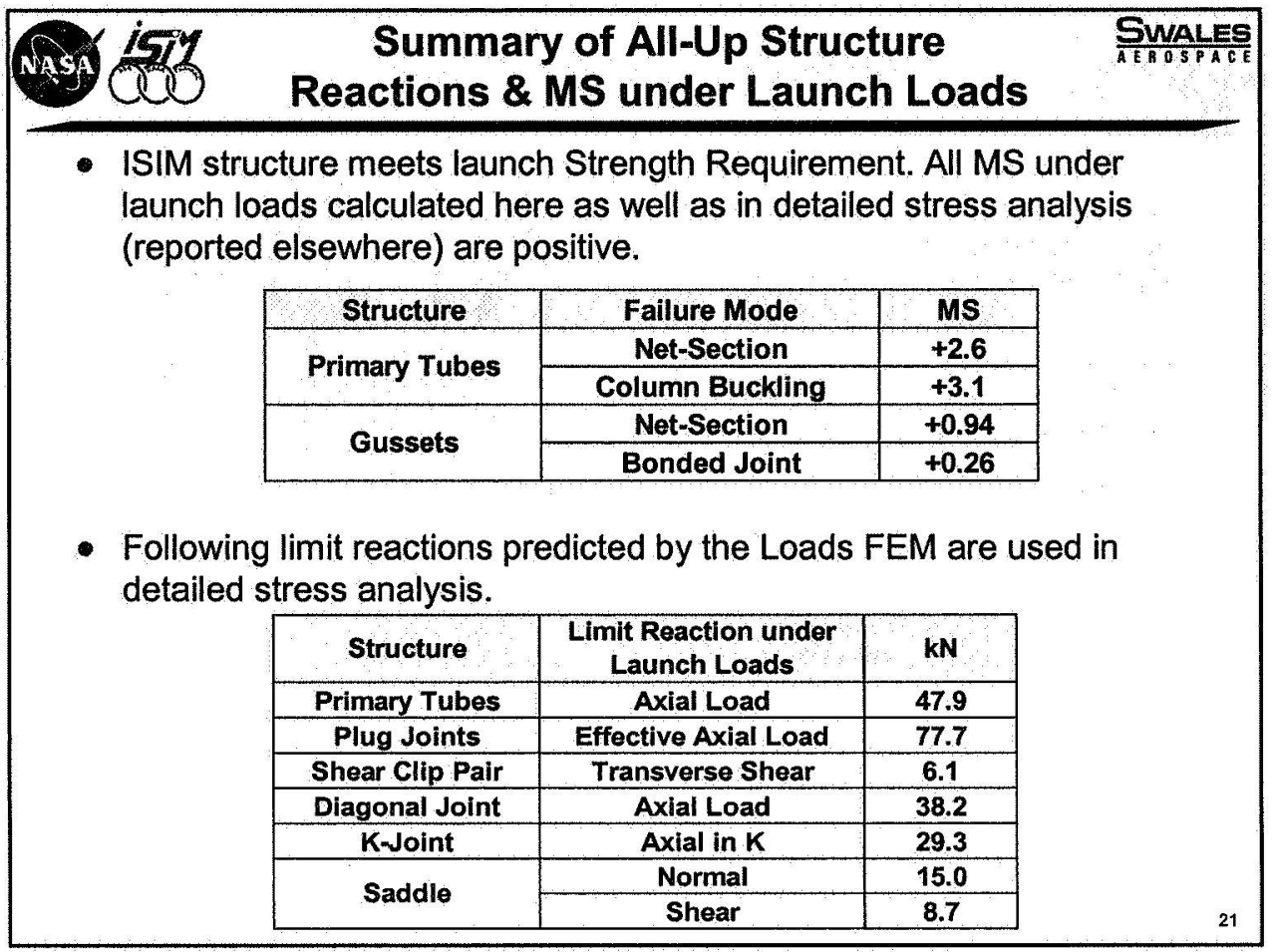

\begin{tabular}{|c|c|c|c|c|c|}
\hline Joint Stre & Analysis Sl & mma & & \multicolumn{2}{|c|}{ SWALES } \\
\hline \multirow{2}{*}{$\begin{array}{l}\text { Detailed stress analysis has been } \\
\text { completed for each of the following } \\
\text { joint types: }\end{array}$} & \multicolumn{5}{|c|}{ Joint Margin Summary } \\
\hline & \multirow[b]{2}{*}{ Joint Type } & \multicolumn{2}{|c|}{ Cool-Down } & \multicolumn{2}{|c|}{ Launch } \\
\hline \multirow{6}{*}{$\begin{array}{l}\text { - Plug joint } \\
\text { - Saddle joint } \\
\text { - Generic T joint } \\
\text { - Slanted T joint } \\
\text { - Neneric K joint } \\
\text { - Diagonal Koint } \\
\text { - KT joint (see picture below) } \\
\text { See Proc. SPIE Vol. } 5868,58680 \mathrm{~K} \\
\text { (Aug. } 19,2005 \text { ) for details on joint } \\
\text { stress analysis. }\end{array}$} & & $\begin{array}{l}\text { failure } \\
\text { mode }\end{array}$ & $\min _{\mathrm{MS}}$ & $\begin{array}{l}\text { failure } \\
\text { mode }\end{array}$ & $\min _{\text {MS }}$ \\
\hline & Plug & $\begin{array}{c}\text { tube } \\
\text { in-plane }\end{array}$ & 0.34 & $\begin{array}{c}\text { tube } \\
\text { in-plane }\end{array}$ & 0.31 \\
\hline & Saddle & $\begin{array}{c}\text { inter- } \\
\text { laminar }\end{array}$ & 0252 & $\begin{array}{c}\text { fube } \\
\text { in-plane }\end{array}$ & 0.52 \\
\hline & $T$, Generic & $\begin{array}{l}\text { Inter- } \\
\text { laminar }\end{array}$ & 0.19 & clip yld & 0.15 \\
\hline & T, Slanted & $\begin{array}{l}\text { inter- } \\
\text { laminar }\end{array}$ & 0.46 & clip yld & 0.14 \\
\hline & K, Generic & $\begin{array}{c}\text { inter- } \\
\text { laminar }\end{array}$ & 0.21 & $\begin{array}{c}\text { tube } \\
\text { in-plane }\end{array}$ & 0.28 \\
\hline stress analysis. & K, NIRSpec & $\begin{array}{l}\text { inter- } \\
\text { laminar }\end{array}$ & 0.04 & clip yid & 0.43 \\
\hline & $\begin{array}{c}\text { Diagonal, } \\
\text { Half Gusset, } 1 \text { Clip } \\
\end{array}$ & $\begin{array}{l}\text { Inter- } \\
\text { laminar }\end{array}$ & 0.02 & clip yld & 0.14 \\
\hline$x^{2}+x$ & $\begin{array}{c}\text { Diagonal, } \\
\text { Full Gusset, } 2 \text { Clips } \\
\end{array}$ & $\begin{array}{l}\text { inter- } \\
\text { laminar }\end{array}$ & 9.03. & clip yld & 0.38 \\
\hline & KT & $\begin{array}{c}\text { inter- } \\
\text { laminar }\end{array}$ & 000 & clip yld & 0.16 \\
\hline
\end{tabular}




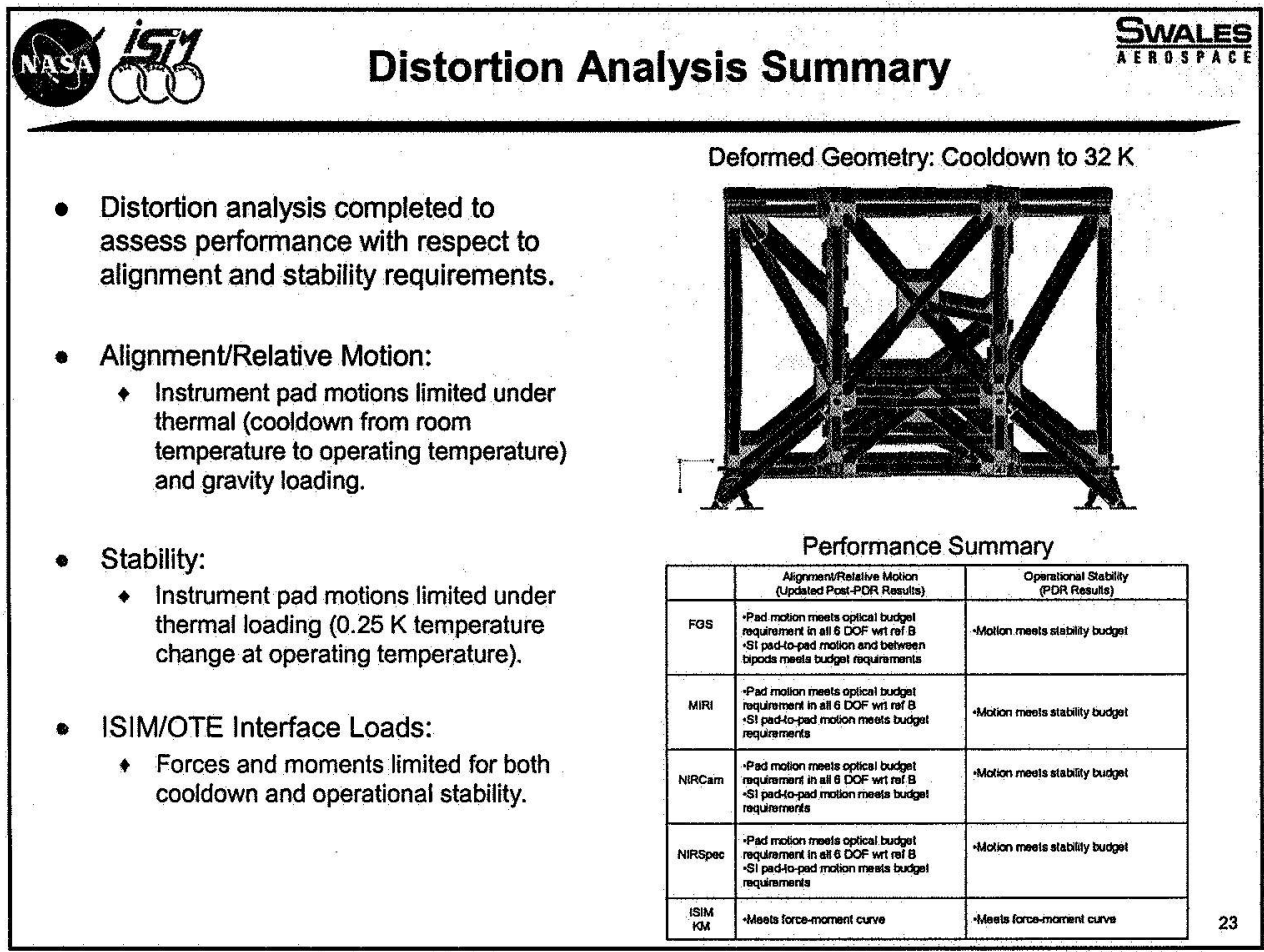

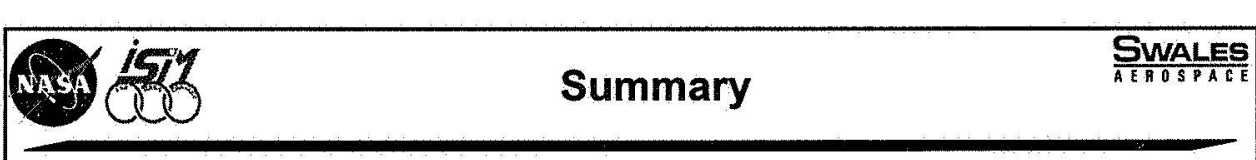

- ISIM primary structure has been designed and sized to meet the challenging requirements of Launch Stiffness \& Strength given:

- Difficult design constraints including;

- SI integration access,

- SI and OTE Interfaces,

- Tight structure weight budget

- And the other conflicting Structural Requirements namely;

- Thermal Survivability under cryogenic cool-down cycles to $22 \mathrm{~K}$

- Alignment Performance under cool-down to and during operation at $32 \mathrm{~K}$

- Simple Loads FEM proved to be very effective \& efficient in guiding structure design

- Concept \& Trade Studies

- Tube wall thickness optimization 